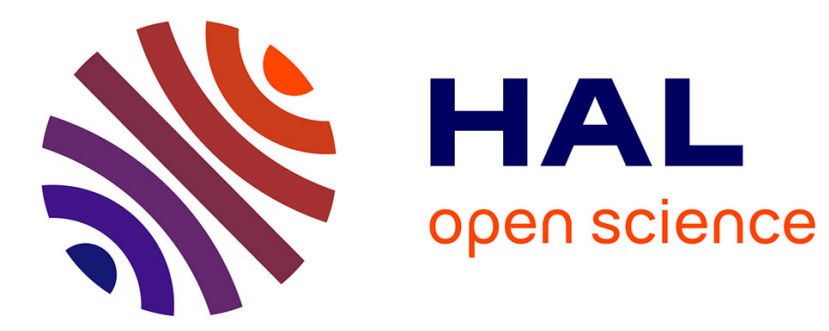

\title{
A review of the metabolic syndrome.
}

Beverley Balkau, Paul Valensi, Eveline Eschwège, Gérard Slama

\section{- To cite this version:}

Beverley Balkau, Paul Valensi, Eveline Eschwège, Gérard Slama. A review of the metabolic syndrome.. Diabetes \& Metabolism, 2007, 33 (6), pp.405-13. 10.1016/j.diabet.2007.08.001 . inserm-00188846

\section{HAL Id: inserm-00188846 https://www.hal.inserm.fr/inserm-00188846}

Submitted on 15 Jan 2008

HAL is a multi-disciplinary open access archive for the deposit and dissemination of scientific research documents, whether they are published or not. The documents may come from teaching and research institutions in France or abroad, or from public or private research centers.
L'archive ouverte pluridisciplinaire HAL, est destinée au dépôt et à la diffusion de documents scientifiques de niveau recherche, publiés ou non, émanant des établissements d'enseignement et de recherche français ou étrangers, des laboratoires publics ou privés. 


\section{HAL author manuscript}

\section{A REVIEW OF THE METABOLIC SYNDROME}

B Balkau ${ }^{1,2}$, P Valensi ${ }^{3}$, E Eschwège $^{1,2}, 6$ Slama $^{4,5}$

${ }^{1}$ INSERM U780-IFR69, Villejuif, France

${ }^{2}$ Univ Paris-Sud, Kremlin-Bicetre, France

${ }^{3}$ Department of Endocrinology, Diabetology and Nutrition, Jean Verdier Hospital, Paris-Nord University, CRNH-IdF France

${ }^{4}$ Paris-Descartes University, Faculty of Medicine, Hôtel-Dieu Hospital, Paris, France

${ }^{5}$ AP-HP, Diagnosis Center, Paris, France

Address correspondence and reprint requests to:

B Balkau

INSERM U780-IFR69

16 Avenue Paul Vaillant Couturier

94807 Villejuif cedex

France

balkau@vjf.inserm.fr 


\section{SUMMARY}

While the concept of this syndrome has been described more than 60 years ago, and more formally almost 20 years ago, the controversy continues as to its utility, which of the various syndrome definitions should be used and their ability to predict diabetes and/or cardiovascular disease. The metabolic syndrome, of cardiovascular risk factors, provides an early warning of at risk subjects and emphasises the need to treat more aggressively (by at least lifestyle modification) patients with multiple abnormalities even though the abnormalities might be slight. Further, the syndrome can be easily used in clinical practice and when it is assessed against the background of the patient's age, sex and smoking habits, it provides an evaluation of potential cardiovascular risk. Prospective intervention studies are the only means of definitively accepting or refuting the usefulness of the syndrome. The metabolic syndrome is an entity which merits attention from both the medical profession and public health authorities.

Key Words: Cardiovascular disease - Diabetes - Insulin resistance - Metabolic syndrome

\section{RESUME}

Voilà plus de 60 ans, le concept de syndrome métabolique a été identifié, et plus formellement décrit il y a une vingtaine d'années. La controverse continue quant à l'utilité d'un tel syndrome, quant à la définition utilisée et à la capacité des différentes définitions à prédire le diabète et/ou les maladies cardio-vasculaires. Le syndrome métabolique indique une alerte précoce pour traiter plus agressivement (au moins par des changements de comportement) les patients porteurs d'anomalies multiples, même si ces anomalies sont modérées. De plus, le syndrome est facile à utiliser en clinique et devrait être mis en parallèle avec l'âge, le sexe et le tabagisme du patient pour l'évaluation du risque cardio-vasculaire. Les études prospectives d'intervention sont les seules études qui fournissent la preuve de l'utilité du syndrome. Le syndrome métabolique mérite toute l'attention de la part du corps médical et des autorités de santé publique.

Mots Clés : Diabète - Insulino-résistance - Maladies cardiovasculaires · Syndrome métabolique 


\section{Introduction}

The metabolic syndrome groups insulin resistance, hyperinsulinaemia, hyperglycaemia, dyslipidaemia (hypertriglyceridaemia and/or hypo HDL-cholesterolaemia), high arterial blood pressure and central adiposity. Other abnormalities are also associated with this constellation and may well also be part of this syndrome. A variety of names have been associated with this condition: the pluri-metabolic syndrome, the insulin-resistance syndrome, syndrome $X$, the dysmetabolic syndrome, the metabolic syndrome ...

In itself insulin resistance is not a disease, but rather a risk factor for the syndrome abnormalities and it has yet to be demonstrated that it is a risk factor for later cardiovascular disease or for diabetes as there are few prospective studies that have measured insulin resistance by a validated method.

At the request of the American Association of Clinical Endocrinologists, in October 2001 the Centre for Disease Control created the code number 277.7 for the dysmetabolic syndrome $X$ in the International Classification of Diseases (ICD-9). This code was recommended to be noted if a physician considered that the syndrome was present in a given individual. However, a report from the United States indicates that the code is little used [1].

\section{History of the syndrome}

In 1988 Gerald Reaven presented the Banting Lecture at the American Diabetes Association meeting. The title of his lecture was "The Role of Insulin Resistance in Human Disease", and the corresponding article was published in the same year [2]. He gave pathophysiological arguments for the existence of a "syndrome $X "$ ", in which he included insulin resistance, hyperinsulinaemia, hyperglycaemia, dyslipidaemia, arterial hypertension. Several years later, during the Claude Bernard Lecture of the European Society for the Study of Diabetes (EASD), Reaven included central adiposity in the syndrome, and noted the importance of free fatty acids [3]. While Reaven's description was based on the pathophysiology of insulin resistance, the syndrome that he described was not precise and it was not possible to identify individuals as having the syndrome: the combination of abnormalities, the number of abnormalities, the thresholds defining the abnormalities were not given. The only abnormality Reaven quantified was insulin resistance, which he affirmed to be present in $25 \%$ of the adult population.

Reaven was not the first to propose such a syndrome. Kylin, in 1923, described the clustering of hypertension, hyperglycaemia and gout [4]. In France, Jean Vague, at the end of the 1940s, documented the association between central adiposity, diabetes, atherosclerosis and 
gout [5,6]. Later, in 1967, Avogaro et al. described a metabolic syndrome [7] and in 1985 Michaela Modan proposed that hyperinsulinaemia was the link between hypertension, obesity and glucose intolerance [8].

Following the description of the syndrome by Reaven, it has become a major theme of research and of public health interest. The number of publications on the subject is ample evidence of the importance given to the syndrome by clinicians and researchers (over 18,000 citations to the "metabolic syndrome" in PubMed, December 2006 - with more than 3,000 citations in 2006 alone).

\section{Arguments for the existence of a syndrome}

The fact that this cluster of abnormalities exists has been well validated by epidemiological studies: the abnormalities cluster more frequently than what would be observed if they clustered by chance [9].

\section{Definitions of the metabolic syndrome}

In the absence of a diagnostic test, a number of definitions of the syndrome have been proposed (Appendix 1). They come from the World Health Organisation (WHO) [10], the European Group for the study of Insulin Resistance (EGIR) [11], J-P Després' group [12], the National Cholesterol Education Program - Adult Treatment Panel III (NCEP-ATP III) [13]. In 2003 the American Association of Clinical Endocrinologists and the American College of Endocrinologists provided a position statement of what they entitled the "insulin resistance syndrome" [14] but they did not give a precise definition, leaving it to a clinician to decide whether a given individual had the syndrome. They recognised that there was no experimental evidence to define diagnostic criteria for the syndrome and consequently their definition could not be precise. They conclude, that the more abnormalities, the more likely that an individual is insulin resistant.

These various definitions include different factors and different thresholds for them. For example the first definition, from the WHO, included microalbuminuria, which does not appear in the later definitions [10]. The EGIR definition [11] did not include diabetic patients, for two reasons - these patients should already be in the health care system, and have their health monitored so identification of the syndrome should not be necessary, and secondly, long standing diabetic patients have lower insulin levels, which do not reflect the level of insulin resistance, a key element of this definition. Finally the simple definition of the 
"hypertriglyceridemic waist" was origially defined only for men, and it has not generally been used as a definition of the syndrome.

The most recent definitions, both in 2005, are from the International Diabetes Federation (IDF) $[15,16]$ and from the American Heart Association/National Heart, Lung, and Blood Institute AHA/NHLBI $[17,18]$.

The differences between these definitions are essentially the thresholds for the parameters to define a syndrome abnormality, the number of abnormalities before the syndrome is deemed to be present, and whether there is a compulsory abnormality which is required to be present.

Reavens' arguments were centred around insulin resistance, and the definitions proposed by the WHO, EGIR and the IDF have taken this into account - WHO because the presence of either insulin resistance or glucose dysregulation were required, EGIR because hyperinsulinaemia was a mandatory factor and for the IDF central obesity (as quantified by the waist circumference) is mandatory, because of the close association between insulin resistance and central adiposity.

The IDF definition, with its differing thresholds for waist circumference according to ethnic group, is likely to become the international norm, as it is supported by several international bodies, however, the more recent American definition will probably be used in the United States.

To define any diagnostic criteria is not easy (for diabetes, the criteria have changed over the years). For a syndrome it is even more complicated - what parameters, what thresholds, what combinations should be used to define it? In fact a score to evaluate the severity of the syndrome, using a combination of continuous variables would be more logical than a syndrome defined with arbitrary thresholds.

\section{Frequency of the syndrome and of its abnormalities}

The frequency of the syndrome differs according to the definition, country, sex, age, and even according to the region in France. From the French MONICA study, the frequency of the NCEPATP III defined syndrome, in men aged 35 to 65 years was $26 \%$ in Lille, $22 \%$ in Strasbourg and $16 \%$ in Toulouse; in women, the corresponding frequencies were $26 \%, 24 \%$ and $13 \%$ [19]. (The definition used included subjects treated by drugs for hypertension and/or for diabetes). In comparison, in the French D.E.S.I.R. Study, of men and women aged 30 to 64 years, the 
corresponding frequencies were $9 \%$ and $6 \%$ and if treatment for diabetes and for hypertension were also included, the frequencies increased to $15 \%$ and to $10 \%$, respectively [20].

Table 1 shows the means and standard deviations of syndrome parameters from a general French population, recruited in Preventive Health Examination Centres in the central western part of France. More details of the reference values, and centiles are given on www.sciencedirect.com These data are for subjects aged 20 to 74 years, and are given by 5-year age classes and by sex; they are from a sample of 130,882 consultants at IRSA (an Institute which provides health screening examinations which are financed by the French social security system). In the tables, the column on the right gives the reference values in a population of 19,126 men and 19,874 women with the same age structure as the French population in the 1999 census, for subjects aged between 20 and 74 years.

In this French population, the frequency of the NCEP-ATP III defined syndrome was $10 \%$ in the men and $9 \%$ in the women, for the IDF definition $21 \%$ and $17 \%$ and for the AHA/NHBLI definition $18 \%$ and $14 \%$ respectively (Table 2 ).

Note that central adiposity is more common in women than in men - because of the choice of the thresholds (Table 2). The NCEP thresholds for the waist ciurcumference $>102 / 88$ for men/women were defined because of their relation with obesity, a BMI $\geq 30 \mathrm{~kg} / \mathrm{m}^{2}$ and/or a high waist-hip ratio $>0.95 / 0.80 \mathrm{men} /$ women [21], and not in relation with the diseases associated with the syndrome, diabetes and cardiovascular disease. The IDF waist thresholds were chosen for the sensitivity/specificity to screen for a BMI $\geq 25 \mathrm{~kg} / \mathrm{m}^{2}$ [21].

Hypo HDL-cholesterolaemia was also defined according to sex, and is more frequent in women than in men.

It has already been noted that in the French D.E.S.I.R. study [20], high arterial blood pressure is more commonly present than in the United States, where the NCEP-ATP III definition was conceived: in men $67 \%$ vs $38 \%$ and in women $44 \%$ vs $29 \%$. Such differences have been documented in a collaborative study where the prevalences of hypertension were $28 \%$ in North American countries in comparison to $44 \%$ in Europe [22].

For the IDF definition of the metabolic syndrome, in comparison with the NCEP-ATP III definition, the definitions of all abnormalities are changed, with an increase in frequency for each abnormality, in comparison with the NCEP-ATP III definition (Table 2). The result is a doubling of the syndrome frequency. The most marked increases in frequency are associated with the waist circumference and fasting glucose (Table 2) where the thresholds have been lowered. For high blood pressure and dyslipidaemia, the changes in frequency are due only to 
the inclusion of the corresponding treatments - little change for high blood pressure, and a close to doubling for both lipid abnormalities; it must be noted that all lipid treatments were included in this analysis, as there was no information as to whether the lipid-lowering therapy was prescribed for treatment of LDL-cholesterol or for triglycerides/HDL-cholesterol.

The AHA/NHLBI definition is similar to the NCEP-ATPIII, with the major difference being the lowering of the glucose threshold, and in consequence a more than three-fold increase in hyperglycaemia.

\section{Consequences of the syndrome}

Reaven described the consequences of the syndrome as cardiovascular disease and diabetes [2].

A meta-analysis of prospective studies quantified the risks of all cause mortality, of morbidity or mortality from cardiovascular diseases and of diabetes from the metabolic syndrome as defined by NCEP-ATP III [23]. The relative risks were estimated as: 1.3 (95\% CI: 0.9-1.8), $1.6(1.3-2.0)$ and 3.0 (1.9-4.6), respectively. These are certainly dependent on the subjects in the study, and if diabetic subjects are included, the risk associated with cardiovascular disease is higher than when they are excluded [24].

There are a number of more recent analyses, one from the Framingham Offspring Cohort showed age-adjusted relative risks for CVD, CHD and type 2 diabetes of 2.9, 2.5 and 6.9 for men, and 2.2, 1.5 and 6.9 for women [25]. In France the D.E.S.I.R. study has shown that the syndrome is predictive of both cardiovascular events and diabetes [26], and in the PRIME study of men from France and northern Ireland, the IDF defined syndrome carried a relative risk for coronary heart disease of 1.41 , the WHO 1.40 and the NCEP 1.46 [27].

While these relative risks may be statistically significant, a risk equation for cardiovascular morbidity or mortality, for example the Framingham or the SCORE risk equations $[28,29]$, are better predictors [30]. However, in the European DECODE study, in men at low risk, with an estimated 10-year risk of cardiovascular mortality under 5\%, the metabolic syndrome had a relative risk of cardiovascular mortality of 2.5 (1.2-5.0) [31,32]. Thus the syndrome provides additional predictive information on CVD risk, over and above that given by a CVD risk score, and involved $9 \%$ of the men. Of the men at high CVD risk (more than $5 \%$ over 10 years, and involving $41 \%$ of the men), the syndrome was present in only one third of them. The hazards ratios of men at high risk of CVD, whether they had the syndrome or not, and those at low risk with the syndrome, were very similar: 2.5, 2.2 and 2.5 respectively, after adjustment for age and the recruitment centre. For women there were fewer cardiovascular events, there 
was no relation, and the relative risk was 1.3 (0.4-4.2). However, the waist alone, with the NCEPATP III thresholds, was associated with higher cardiovascular mortality: 2.2 (1.1-4.8) in men and 2.3 (0.8-6.7) in women, after adjustment for age and recruitment centre, and these two risks were not significantly different.

The metabolic sydnrome carries a much higher risk for diabetes than for CVD. To predict incident diabetes, the traditional risk markers of diabetes, such as glucose concentrations perform better than the metabolic syndrome [30, 33]. But in the Framingham Offspring Study [25], while high fasting glucose carried a hazards ratio of 12.5 (9.1-17.3) for high glucose alone, the syndrome had a hazards ratio of 11.0 (8.1-14.9), and the hazards ratio was still high, 5.0 (3.7-6.8) if the syndrome was present, but the glucose level low $<6.1 \mathrm{mmol} / \mathrm{l}$.

Other consequences of the syndrome are hypertension, polycystic ovary syndrome, nonalcoholic steatosis and chronic renal disease.

\section{Treatment of the syndrome}

As the syndrome does not have a known cause, the cause is not able to be treated.

To delay the appearance of the syndrome or its manifestations, insulin sensitivity could be targeted, by lifestyle modification - loss of weight, increase in physical activity, a healthy diet or by pharmacological intervention. There are several medications which target insulin sensitivity (Thiazolidinediones, Metformin, ... ) and others which help in weight loss (Orlistat, Sibutramine, Rimonabant). In the future, there will be more evidence to elucidate whether these treatments are effective in delaying the appearance of the metabolic syndrome and in the patients with the syndrome, in preventing CVD and diabetes.

To treat the abnormalities of the metabolic syndrome, the first step is lifestyle modification and modest weight may be effective [34]. Drug treatment should be used for the specific abnormalities according to current guidelines, and a more aggressive approach may be appropriate when more than one abnormality is present.

Statement from the European Association for the Study of Diabetes and the American Diabetes Association, 2005

This joint statement gave a "critical appraisal' of the metabolic syndrome [35]. It concluded: "Until much-needed research is completed, clinicians should evaluate and treat all CVD risk factors without regard to whether a patient meets the criteria for diagnosis of the "metabolic 
syndrome". The review aimed to argue four points, which are given below along with our responses, given in italics:

1. "the metabolic syndrome is not nearly as well defined and characterized as is often assumed" RESPONSE:

The syndrome is certainly not well defined, and it was Reaven who was initially (perhaps deliberately) vague with his description of the syndrome [2]. The multiplicity of definitions for the syndrome has resulted in confusion and has led to a lack of credibility for the concept as a whole.

2. "the notion that it is a useful marker of CVD risk above and beyond the risk associated with its individual components is uncertain"

RESPONSE

That the individual components of the syndrome may carry a similar or even higher risk than the syndrome has been illustrated in the DECODE study [32]; these analyses also show that men at lower estimated risk of cardiovascular death ( $\$ 5 \%$ in 10 years according to the SCORE risk equations), who have the syndrome, are at high risk of fatal CVD, of equivalent risk to those at higher risk of CVD death, according the European CVD Score equation. Thus, the syndrome - or at least the components in the syndrome that are not included in a classical CVD risk score (waist circumference in particular) - identifies a group of men at risk. This was not the case in the women, but waist circumference was a good marker of fatal CVD risk, in the women at low risk ( $5 \%$ in 10 years).

While CVD risk scores appear to be more closely related with CVD outcomes than the syndrome [30], they are rarely used in clinical practice. The syndrome is an easy concept enabling a physician to identify patients at risk, with routinely available measures. The thresholds of the various parameters enable a quick categorisation of patients, with a large waist circumference being a clear first step, which should prompt the search for the cluster of metabolic abnormalities. If age, sex and smoking are taken into account along with the syndrome abnormalities, the cardiovascular risk can be assessed. An evaluation needs to be made of the severity of the various abnormalities, and each one may not carry the same importance.

Further, the promotion of the concept of the metabolic syndrome has drawn attention to the fact that patients diagnosed with diabetes, hypertension or lipids, should be investigated for other abnormalities in the metabolic syndrome cluster. 
3. "although certain CVD risk factors undoubtedly occur together more often than expected, the underlying pathophysiology of the syndrome is unclear"

\section{RESPONSE}

The clustering of the CVD risk factors, the syndrome abnormalities cannot be disputed - and research is needed to elucidate the reasons for this clustering. Given current knowledge, drug treatment can only be factor by factor, with appropriate care to choose the treatments which do not aggravate the other abnormalities. Research will provide more information, and may also provide new molecules to treat the syndrome as a cluster, rather than treating the individual abnormalities. In the meantime, the outcome is treated, without consideration of the physiology which has led to the condition. Treatment should target insulin sensitivity: increase in physical activity and weight loss, and possibly some drugs in the future.

4. "the list of risk factors comprising the cluster is not grounded by well-defined criteria" They then state that "the manuscript is a cautionary reminder to practitioners, and an urgent call for further research."

\section{RESPONSE}

The abnormalities proposed for the definitions of the syndrome have been chosen following Reaven [2], and other components have been added or proposed because of their close correlation with insulin concentrations or insulin resistance indexes. As argued above, the choice of the components, their thresholds or the number of them required for the syndrome is all rather arbitrary. Each of the syndrome parameters has a continuous relation with cardiovascular disease incidence, thus it is difficult to define a threshold on this basis. The combination of abnormalities is also difficult to justify, as is the inclusion of other possible related abnormalities.

\section{Other arguments pro- and con for the syndrome}

In a similar vein, a recent article by Reaven is entitled "The Metabolic Syndrome: Requiescat in Pace" [36]. His arguments are targeted on insulin resistance and its relation with clinically significant disease with the aim of understanding the pathophysiology. Insulin resistance can exist without metabolic clustering. However, Reaven does argue that there is a benefit in diagnosing a syndrome to initiate lifestyle changes, but that the use of a precise definition, 
given the arbitrary nature of the thresholds, may not be appropriate. The diagnosis of diabetes relies on somewhat arbitrary, consensual thresholds, and has long proved its usefulness.

Greenland poses the clinical question as to whether patient outcome is improved by identification of the syndrome - rather than by a classical global CVD risk score [37].

The American Heart Association, in particular Grundy et al. [17, 18, 38], and Eckel et al. [39], have argued both in scientific journals and in internet newsletters about the utility of the syndrome and provided guidelines for its management.

\section{Conclusion.}

While awaiting further knowledge on the causes of the abnormalities of the metabolic syndrome and of the metabolic syndrome itself, the metabolic syndrome should be recognized as an entity which deserves attention from the medical profession and public health authorities. The metabolic syndrome provides an early, simple and cheap warning of patients at risk of cardiovascular disease and diabetes, and emphasizes the need to treat more aggressively those with multiple abnormalities, even though individually these abnormalities may be slight. While there is no clinical trial evidence for the efficacy of such an approach, it is in line, for example, with recommendations for the more aggressive treatment of lipids and hypertension in diabetic patients. In all cases, the first-line treatment consists of lifestyle modification. Drug treatments should be used according to current recommendations for each individual risk factor. Additional research is needed to identify new targets for treatments to prevent cardiovascular disease, in particular other lipid goals, such as increasing HDL-cholesterol levels once the LDLcholesterol goal is achieved.

In clinical practice either the NCEP-ATP III or the IDF or the AHA/NHBLI definitions of the syndrome could be used: the fact that the thresholds and the combinations of abnormalities might be arbitrary does not prevent the use of the concept. For epidemiological studies, it would be preferable to report frequencies and outcomes for all three definitions. The AHA/NHBLI definition, which retains the higher thresholds values for waist circumference is likely, to be adopted in the United States $[17,18]$. Certainly, the recognition of a high waist circumference as a first abnormality, as in the IDF definition of the syndrome, will enable a quick screening of subjects at risk for cardiovascular disease and for diabetes. 


\section{Acknowledgements.}

The data and the analyses determining the reference values of the parameters of the metabolic syndrome and the frequencies of the metabolic syndrome components and the syndrome itself, have been provided by J Tichet and S Vol from the Institut inter Régional pour la Santé (IRSA, France). 


\section{References}

1. Ford ES. Rarer than a blue moon: the use of a diagnostic code for the metabolic syndrome in the U.S. Diabetes Care 2005;28:1808-9

2. Reaven GM. Banting lecture 1988. Role of insulin resistance in human disease. Diabetes $1988 ; 37: 1595-607$

3. Reaven GM. The fourth musketeer--from Alexandre Dumas to Claude Bernard. Diabetologia 1995:38:3-13

4. Kylin E. Studien über das Hypertonie-Hyperglykämie-Hyperurika miesyndrom. Zentralblat† für Innere Medizin 1923;44:105-127

5. Vague J. The degree of masculine differentiation of obesities: a factor determining predisposition to diabetes, atherosclerosis, gout, and uric calculous disease. Am J Clin Nutr 1956;4:20-34.

6. Vague J. Sexual differentiation. A determinant factor of the forms of obesity. 1947. Obes Res 1996:4:201-3

7. Avogaro P, Crepaldi G, Enzi G, Tiengo A. Associazione di iperlipidemia, diabete mellito $e$ obesita de medio grado. Acto Diabetol Lat 1967;4:36-41

8. Modan M, Halkin $H$, Almog S, Lusky A, Eshkol A, Shefi M, Shitrit A, Fuchs Z. Hyperinsulinemia. A link between hypertension obesity and glucose intolerance. $J$ Clin Invest 1985:75:809-17

9. Ferrannini E, Haffner SM, Mitchell BD, Stern MP. Hyperinsulinaemia: the key feature of a cardiovascular and metabolic syndrome. Diabetologia 1991;34:416-22

10. World Health Organisation. Definition, diagnosis and classification of diabetes mellitus and its complications. Report of a WHO consultation, 1999

11. Balkau B, Charles MA. Comment on the provisional report from the WHO consultation. European Group for the Study of Insulin Resistance (EGIR) Diabet Med 1999; 16:442-3.

12. Lemieux I, Pascot A, Couillard C, Lamarche B, Tchernof A, Almeras N, Bergeron J, Gaudet D, Tremblay G, Prud'homme D, Nadeau A, Despres JP. Hypertriglyceridemic waist: A marker of the atherogenic metabolic triad (hyperinsulinemia; hyperapolipoprotein B; small, dense LDL) in men? Circulation 2000:102:179-84.

13. Expert Panel on Detection, Evaluation, and Treatment of High Blood Cholesterol in Adults. Executive Summary of the Third Report of the National Cholesterol Education Program (NCEP) Expert Panel on Detection, Evaluation, and Treatment of High Blood Cholesterol in Adults (Adult Treatment Panel III). JAMA 2001:285:2486-97 
14. Einhorn D, Reaven GM, Cobin RH, Ford E, Ganda OP, Handelsman Y, Hellman R, Jellinger PS, Kendall D, Krauss RM, Neufeld ND, Petak SM, Rodbard HW, Seibel JA, Smith DA, Wilson PW. American College of Endocrinology position statement on the insulin resistance syndrome. Endocr Pract 2003:9:237-52

15. IDF Consensus group. http://www.idf.org/webdata/docs/IDF_Metasyndrome_definition.pdf, December 2006

16. Alberti KG, Zimmet P, Shaw J; IDF Epidemiology Task Force Consensus Group. The metabolic syndrome--a new worldwide definition. Lancet 2005;366:1059-62

17. Grundy SM, Cleeman JI, Daniels SR, Donato KA, Eckel RH, Franklin BA, Gordon DJ, Krauss RM, Savage PJ, Smith SC Jr, Spertus JA, Costa F. Diagnosis and Management of the Metabolic Syndrome. An American Heart. Association/National Heart, Lung, and Blood Institute Scientific Statement. Circulation 2005;112:2735-52

18. Grundy SM, Cleeman JI, Daniels SR, Donato KA, Eckel RH, Franklin BA, Gordon DJ, KrausS RM, Savage PJ, Smith SC Jr, Spertus JA, Costa F. Diagnosis and Management of the Metabolic Syndrome. An American Heart Association/National Heart, Lung, and Blood Institute Scientific Statement. Executive Summary. Circulation 2005;112:e285-90

19. Gomila S, Dallongeville J. Epidémiologie du syndrome métabolique en France. Med Nutr, 2003:39:89-94

20. Balkau B, Vernay M, Mhamdi L, Novak M, Arondel D, Vol S, Tichet J, Eschwege E; D.E.S.I.R. Study Group. The incidence and persistence of the NCEP (National Cholesterol Education Program) metabolic syndrome. The French D.E.S.I.R. study. Diabetes Metab 2003:29:526-32

21. Lean ME, Han TS, Morrison CE. Waist circumference as a measure for indicating need for weight management. BMJ 1995;311:158-61

22. Wolf-Maier K, Cooper RS, Banegas JR, Giampaoli S, Hense HW, Joffres M, Kastarinen M, Poulter N, Primatesta P, Rodriguez-Artalejo F, Stegmayr B, Thamm M, Tuomilehto J, Vanuzzo D, Vescio F. Hypertension prevalence and blood pressure levels in 6 European countries, Canada, and the United States. JAMA 2003:289:2363-9

23. Ford ES. Risks for all-cause mortality, cardiovascular disease, and diabetes associated with the metabolic syndrome: a summary of the evidence. Diabetes Care 2005;28:1769-78

24. Stern MP, Williams K, Hunt KJ. Impact of diabetes/metabolic syndrome in patients with established cardiovascular disease. Atheroscler Suppl 2005;6:3-6 
25. Wilson PW, D'Agostino RB, Parise H, Sullivan L, Meigs JB. Metabolic syndrome as a precursor of cardiovascular disease and type 2 diabetes mellitus. Circulation 2005;112:3066-72

26. Hillier TA, Rousseau $A$, Lange $C$, Lepinay $P$, Cailleau $M$, Novak M, Calliez $E$, Ducimetiere $P$, Balkau B. Practical way to assess metabolic syndrome using a continuous score obtained from principal components analysis : The D.E.S.I.R. Cohort. Diabetologia 2006:49:1528-35

27. Bataille V, Perret B, Dallongeville J, Arveiler D, Yarnell J, Ducimetiere P, Ferrieres J. Metabolic syndrome and coronary heart disease risk in a population-based study of middle-aged men from France and Northern Ireland. A nested case-control study from the PRIME cohort. Diabetes Metab 2006:32:475-9

28. Wilson PW, D'Agostino RB, Levy D, Belanger AM, Silbershatz H, Kannel WB. Prediction of coronary heart disease using risk factor categories. Circulation 1998;97:1837-47

29. Conroy RM, Pyorala K, Fitzgerald AP, Sans S, Menotti A, De Backer G, De Bacquer D, Ducimetiere P, Jousilahti P, Keil U, Njolstad I, Oganov RG, ThomsenT, Tunstall-Pedoe H, Tverdal A, Wedel $H$, Whincup P, Wilhelmsen L, Graham IM; SCORE project group. Estimation of ten-year risk of fatal cardiovascular disease in Europe: the SCORE project. Eur Heart J 2003:24:987-1003

30. Stern MP, Williams K, Gonzalez-Villalpando C, Hunt KJ, Haffner SM. Does the metabolic syndrome improve identification of individuals at risk of type 2 diabetes and/or cardiovascular disease? Diabetes Care 2004;27:2676-2681

31. Balkau B, Qiao Q, Tuomilehto J, Borch-Johnsen K, Pyöralä K. Does the metabolic syndrome detect further subjects at high risk of cardiovascular death, or is a conventional cardiovascular risk score adequate? Diabetologia 2005;48:A119

32. The DECODE Study Group. Does the diagnosis of the metabolic syndrome in non-diabetic men detect further subjects at high risk of cardiovascular death beyond those identified by a conventional cardiovascular risk score? The DECODE Study. Eur J Cardiovasc Prev Rehabil 2007;14:192-199

33. Hanson RL, Imperatore G, Bennett PH, Knowler WC. Components of the "metabolic syndrome" and incidence of type 2 diabetes. Diabetes 2002:51:3120-3127

34. Hillier TA, Fagot-Campagna A, Eschwège E, Vol S, Cailleau M, Balkau B and the D.E.S.I.R. Study group. Weight change and changes in the metabolic syndrome as the French population moves towards overweight: The D.E.S.I.R. Cohort. Int $J$ Epidemiol 2006:35:190-196 
35. Kahn R, Buse J, Ferrannini E, Stern M. The metabolic syndrome: time for a critical appraisal: joint statement from the American Diabetes Association and the European Association for the Study of Diabetes. Diabetes Care 2005:28:2289-304. Diabetologia 2005:48:1684-99

36. Reaven GM. The metabolic syndrome: requiescat in pace. Clin Chem 2005;51:931-8.

37. Greenland P. Critical questions about the metabolic syndrome. Circulation 2005;112:3675-6

38. Grundy SM. Does the Metabolic Syndrome exist? Diabetes Care 2006:29:1689-92

39. Eckel RH, Grundy SM, Zimmet PZ. The metabolic syndrome. Lancet 2005;365:1415-28 
Table 1

Means and standard deviations (SD), according to age, of parameters included in the metabolic syndrome in a population of 130,882 consultants, 65,372 men and 65,510 women, in 2002-2004 at the "Institut inter Régional de la Santé", (IRSA) an Institute in central-western France which provides health examinations. The last column shows the reference values for a population aged 20-74 years with the same age structure as the French population in the 1999 census. More complete information with the distribution of the percentiles is available at www.xxxxxx. 


\begin{tabular}{|c|c|c|c|c|c|c|c|c|c|c|c|c|c|}
\hline \multirow{3}{*}{ MEN } & & \multicolumn{12}{|c|}{ Age (years) } \\
\hline & & $20-24$ & $25-29$ & $30-34$ & $35-39$ & $40-44$ & $45-49$ & $50-54$ & $55-59$ & $60-64$ & $65-69$ & $70-74$ & $20-74$ \\
\hline & & $n=3436$ & $n=4812$ & $n=7068$ & $n=8850$ & $n=8885$ & $n=9077$ & $n=9038$ & $n=6474$ & $n=3649$ & $n=2684$ & $n=1399$ & $n=19126$ \\
\hline \multirow{2}{*}{ WAIST $(\mathrm{cm})$} & mean & 79 & 83 & 86 & 88 & 89 & 91 & 93 & 94 & 95 & 96 & 97 & 89 \\
\hline & SD & 9 & 10 & 10 & 10 & 10 & 10 & 10 & 10 & 10 & 10 & 10 & 11 \\
\hline \multirow{2}{*}{ GLUCOSE $(g / l)$} & mean & 0.91 & 0.92 & 0.94 & 0.96 & 0.98 & 1.00 & 1.02 & 1.04 & 1.03 & 1.04 & 1.05 & 0.98 \\
\hline & SD & 0.11 & 0.10 & 0.11 & 0.12 & 0.14 & 0.16 & 0.19 & 0.21 & 0.21 & 0.22 & 0.25 & 0.17 \\
\hline TRIGLYCERIDES & mean & 0.84 & 0.93 & 1.01 & 1.06 & 1.11 & 1.14 & 1.15 & 1.14 & 1.12 & 1.09 & 1.10 & 1.06 \\
\hline$(g / l)$ & SD & 0.47 & 0.56 & 0.64 & 0.63 & 0.67 & 0.66 & 0.66 & 0.65 & 0.59 & 0.53 & 0.53 & 0.62 \\
\hline HDL-CHOLESTEROL & mean & 0.51 & 0.53 & 0.53 & 0.54 & 0.55 & 0.56 & 0.56 & 0.56 & 0.56 & 0.56 & 0.56 & 0.55 \\
\hline$(g / l)$ & SD & 0.12 & 0.13 & 0.13 & 0.13 & 0.14 & 0.14 & 0.14 & 0.13 & 0.14 & 0.13 & 0.14 & 0.13 \\
\hline SYSTOLIC BLOOD & mean & 127 & 128 & 128 & 129 & 131 & 134 & 137 & 140 & 142 & 146 & 148 & 134 \\
\hline PRESSURE $(\mathrm{mmHg})$ & SD & 10 & 11 & 11 & 12 & 13 & 14 & 15 & 16 & 17 & 18 & 18 & 15 \\
\hline DIASTOLIC BLOOD & mean & 73 & 75 & 76 & 78 & 80 & 82 & 83 & 84 & 84 & 84 & 83 & 80 \\
\hline PRESSURE $(\mathrm{mmHg})$ & SD & 8 & 8 & 8 & 9 & 9 & 10 & 10 & 10 & 10 & 10 & 10 & 10 \\
\hline
\end{tabular}




\begin{tabular}{|c|c|c|c|c|c|c|c|c|c|c|c|c|c|}
\hline \multirow{3}{*}{ WOMEN } & & \multicolumn{12}{|c|}{ Age (years) } \\
\hline & & $20-24$ & $25-29$ & $30-34$ & $35-39$ & $40-44$ & $45-49$ & $50-54$ & $55-59$ & $60-64$ & $65-69$ & $70-74$ & $20-74$ \\
\hline & & $n=5261$ & $n=5398$ & $n=7264$ & $n=7368$ & $n=8558$ & $n=8879$ & $n=8619$ & $n=6655$ & $n=3509$ & $n=2580$ & $n=1419$ & $n=19874$ \\
\hline \multirow{2}{*}{ WAIST $(\mathrm{cm})$} & mean & 72 & 74 & 76 & 77 & 78 & 79 & 81 & 83 & 84 & 85 & 86 & 79 \\
\hline & $S D$ & 10 & 11 & 11 & 11 & 11 & 12 & 12 & 12 & 12 & 12 & 12 & 12 \\
\hline \multirow{2}{*}{ GLUCOSE $(g / l)$} & mean & 0.87 & 0.87 & 0.89 & 0.90 & 0.92 & 0.94 & 0.95 & 0.96 & 0.97 & 0.97 & 0.99 & 0.93 \\
\hline & SD & 0.10 & 0.10 & 0.10 & 0.11 & 0.12 & 0.15 & 0.15 & 0.16 & 0.17 & 0.19 & 0.20 & 0.15 \\
\hline TRIGLYCERIDES & mean & 0.83 & 0.80 & 0.79 & 0.78 & 0.79 & 0.82 & 0.85 & 0.93 & 0.97 & 0.98 & 1.02 & 0.85 \\
\hline$(g / l)$ & SD & 0.36 & 0.38 & 0.38 & 0.39 & 0.40 & 0.45 & 0.44 & 0.47 & 0.48 & 0.46 & 0.51 & 0.43 \\
\hline HDL-CHOLESTEROL & mean & 0.59 & 0.61 & 0.61 & 0.63 & 0.64 & 0.65 & 0.67 & 0.67 & 0.67 & 0.67 & 0.66 & 0.64 \\
\hline$(g / l)$ & SD & 0.14 & 0.15 & 0.14 & 0.15 & 0.15 & 0.15 & 0.16 & 0.16 & 0.16 & 0.16 & 0.16 & 0.15 \\
\hline SYSTOLIC BLOOD & mean & 118 & 117 & 117 & 118 & 121 & 125 & 128 & 132 & 136 & 139 & 143 & 126 \\
\hline \multirow[t]{2}{*}{ PRESSURE $(\mathrm{mmH})$} & SD & 10 & 11 & 12 & 12 & 14 & 15 & 15 & 16 & 16 & 17 & 18 & 16 \\
\hline & mean & 71 & 72 & 72 & 74 & 76 & 77 & 78 & 79 & 80 & 80 & 80 & 76 \\
\hline
\end{tabular}




\begin{tabular}{|c|c|c|c|c|c|c|c|c|c|c|c|c|c|}
\hline DIASTOLIC BLOOD & mean & 71 & 72 & 72 & 74 & 76 & 77 & 78 & 79 & 80 & 80 & 80 & 76 \\
\hline PRESSURE $(\mathrm{mmHg})$ & SD & 8 & 8 & 9 & 9 & 9 & 10 & 9 & 9 & 9 & 9 & 9 & 10 \\
\hline
\end{tabular}




\section{Table 2}

Frequency of the metabolic syndrome abnormalities and frequency of the syndrome defined according to the NCEP-ATP III, the IDF and the AHA/NHLBI definitions, in a sample of consultants from IRSA (French Health Examination Centres) in 2002-2004. These men and women, aged 20 to 74 years, had the same age structure as the French population in the 1999 census.

NCEP-ATP III defined metabolic syndrome.

MEN WOMEN

$$
n=19126 \quad n=19874
$$

Waist circumference $>102 / 88 \mathrm{~cm}$

$12 \%$

$20 \%$

Fasting glucose $\geq 1.10 \mathrm{~g} / \mathrm{l}$

$12 \%$

$6 \%$

Blood pressure $\geq 130 / \geq 85 \mathrm{mmHg}$

$66 \%$

$43 \%$

Triglycerides $\geq 1.50 \mathrm{~g} / \mathrm{l}$

$17 \%$

$7 \%$

HDL-cholesterol $<0.40 / 0.50 \mathrm{~g} / \mathrm{I}$

$10 \%$

$18 \%$

NCEP-ATP III syndrome present

$10 \%$

$9 \%$

\section{IDF defined metabolic syndrome}

\section{MEN}

WOMEN

\begin{tabular}{|c|c|c|}
\hline & $n=19126$ & $n=19874$ \\
\hline Waist circumference $\geq 94 / 80 \mathrm{~cm}$ & $33 \%$ & $40 \%$ \\
\hline $\begin{array}{l}\text { Fasting glucose } \geq 1.00 \mathrm{~g} / \mathrm{l} \text { or previously diagnosed } \\
\text { type } 2 \text { diabetes }\end{array}$ & $35 \%$ & $18 \%$ \\
\hline \multicolumn{3}{|l|}{ Raised blood pressure: } \\
\hline $\begin{array}{l}S B P \geq 130 \text { or } D B P \geq 85 \mathrm{mmHg} \text { or treatment of } \\
\text { previously diagnosed hypertension }\end{array}$ & $67 \%$ & $44 \%$ \\
\hline $\begin{array}{l}\text { Raised triglycerides } \geq 1.5 \mathrm{~g} / \mathrm{l} \text { or a specific treatment } \\
\text { for this lipid abnormality* }\end{array}$ & $23 \%$ & $14 \%$ \\
\hline $\begin{array}{l}\text { Reduced HDL-cholesterol }<0.4 / 0.5 \mathrm{~g} / \mathrm{l} \text { (men/women) } \\
\text { or a specific treatment for this lipid abnormality* }\end{array}$ & $18 \%$ & $24 \%$ \\
\hline IDF syndrome present‡ & $21 \%$ & $17 \%$ \\
\hline
\end{tabular}

* any lipid treatment was included here

₹ if treated for lipids, only counted for the hypertriglyceridaemia abnormality 
Waist circumference $\geq 102 / 88 \mathrm{~cm}$

Fasting glucose $\geq 1.00 \mathrm{~g} / \mathrm{l}$ or previously diagnosed type 2 diabetes

Raised blood pressure:

$S B P \geq 130$ or $D B P \geq 85 \mathrm{mmHg}$ or drug treatment

for hypertension

Raised triglycerides $\geq 1.5 \mathrm{~g} / \mathrm{l}$ or drug treatment for elevated triglycerides

Reduced HDL-cholesterol < 0.4/0.5 g/l (men/women) or drug treatment for reduced HDL cholesterol

AHA/NHLBI syndrome present‡

* any lipid treatment was included here

₹ if treated for lipids, only counted for the hypertriglyceridaemia abnormality 


\section{Appendix 1}

\section{DEFINITIONS OF THE SYNDROME}

WHO definition of the metabolic syndrome, 1999 [10]

Glucose intolerance, IGT or diabetes mellitus and/or insulin resistance together with two or more of the other components listed below:

- Impaired glucose regulation or diabetes

- Insulin resistance (under hyperinsulinaemic, euglycaemic conditions, glucose uptake below lowest quartile for background population under investigation)

- Raised arterial pressure $\geq 140 / 90 \mathrm{~mm}$

- Raised plasma triglycerides ( $\geq 1.7 \mathrm{mmol} / \mathrm{l}$ (1.5 g/l) and/or low HDL-cholesterol (< $0.9 \mathrm{mmol} / \mathrm{I}$ $(0.35 \mathrm{~g} / \mathrm{l})$ men: $<1.0 \mathrm{mmol} / \mathrm{l}(0.39 \mathrm{~g} / \mathrm{l})$ women $)$

- Central obesity: (men: waist to hip ratio > 0.90; women: waist to hip ratio > 0.85 and/or $B M I>30 \mathrm{~kg} / \mathrm{m}^{2}$

- Microalbuminuria (urinary albumin excretion rate $\geq 20 \mu \mathrm{g} / \mathrm{min}$ or albumin:creatinine ratio $\geq 30 \mathrm{mg} / \mathrm{g}$ )

\section{EGIR Syndrome d'Insulino-Résistance, 1999 [11]}

Defined only for non-diabetic subjects.

Insulin-resistance (defined by hyperinsulinaemia - above the third quartile of the fasting insulin concentration in non-diabetic subjects, sexes and all ages combined) plus two abnormalities among:

- Central obesity: waist circumference $\geq 94 / 80 \mathrm{~cm}$ (men / women)

- Dyslipidaemia: high triglycerides: $\geq 2.0 \mathrm{mmol} / \mathrm{l}(1.8 \mathrm{~g} / \mathrm{l})$ and/or low HDL-cholesterol: < 1.0 $\mathrm{mmol} / \mathrm{l}(0.40 \mathrm{~g} / \mathrm{l})$ or treatment for dyslipidaemia

- Hyperglycaemia: fasting plasma glucose $\geq 6.1 \mathrm{mmol} / \mathrm{l}(1.1 \mathrm{~g} / \mathrm{l})$ but $<7.0 \mathrm{mmol} / \mathrm{l}(1.26 \mathrm{~g} / \mathrm{l})$

- Hypertension: systolic/diastolic $\geq 140$ and/or $90 \mathrm{mmHg}$ or treatment for hypertension

Després' Group, the hypertriglyceridemic waist, 2000 [12]

Defined only for men

- Waist $\geq 90 \mathrm{~cm}$

- Triglycerides $\geq 2.0 \mathrm{mmol} / \mathrm{l}(1.75 \mathrm{~g} / \mathrm{l})$ 
NCEP-ATP III definition of the metabolic syndrome, 2001 [13]

Three or more of the following risk factors:

- Abdominal obesity: waist circumference > $102 / 88 \mathrm{~cm}$ (men/women)

- Triglycerides $\geq 1.50 \mathrm{~g} / \mathrm{l}(1.69 \mathrm{mmol} / \mathrm{l})$

- HDL-cholesterol < $0.40 / 0.50 \mathrm{~g} / \mathrm{l}(1.04 / 1.29 \mathrm{mmol} / \mathrm{l})$ (men/women)

- Blood pressure $\geq 130 / \geq 85 \mathrm{mmHg}$

- Fasting glucose $\geqq 1.10 \mathrm{~g} / \mathrm{l}(6.1 \mathrm{mmol} / \mathrm{l})$

American Association of Clinical Endocrinology, American College of Endocrinology (ACE) [14]

ACE Position Statement on the insulin resistance syndrome*, 2002

- Abnormalities of the insulin resistance syndrome

- Triglycerides $\geq 1.50 \mathrm{~g} / \mathrm{l}(1.7 \mathrm{mmol} / \mathrm{l})$

- HDL-cholesterol < $0.40 / 0.50 \mathrm{~g} / \mathrm{l}$ (1.04/ $1.29 \mathrm{mmol} / \mathrm{l})$ (men/women)

- Blood pressure > $130 / 85 \mathrm{mmHg}$

- Glucose: fasting $1.10-1.25 \mathrm{~g} / \mathrm{l}(6.1-6.9 \mathrm{mmol} / \mathrm{l}), 2$ hours post-glucose challenge $1.40-2.00$ $\mathrm{g} / \mathrm{l}(7.8-11.1 \mathrm{mmol} / \mathrm{l})$

*The diagnosis of the insulin resistance syndrome must be based on the professional opinion of the physician. 


\section{International Diabetes Federation (IDF) $[15,16]$}

Consensus worldwide definition of the metabolic syndrome, 2005

Central obesity ${ }^{\star}$ - ethnic specific

Europids $\geq 94 / 80 \mathrm{~cm}$ (men / women) (In the USA the ATP III (102 male, 88 female) are likely to be used for clinical purposes)

South Asians $\geq 90 / 80 \mathrm{~cm}$ (men / women)

Chinese $\geq 90 / 80 \mathrm{~cm}$ (men / women)

Japan $\geq 85 / 90 \mathrm{~cm}$ (men / women)

Ethnic Central and South Americans: use South Asians recommendations

Sub-Saharan Africans: use Europid recommendations

Eastern Mediterranean and Middle East (Arab): use Europid recommendations

plus any two of the following four factors:

- raised triglycerides level: $\geq 1.50 \mathrm{~g} / \mathrm{l}(1.7 \mathrm{mmol} / \mathrm{l})$ or a specific treatment for this lipid abnormality (given as $>1.50 \mathrm{~g} / \mathrm{d}$ in [16])

- reduced HDL-cholesterol: < 0.40/0.50 g/l (1.03/ $1.29 \mathrm{mmol} / \mathrm{l})$ (men/women) or a treatment specific for this lipid abnormality

- raised blood pressure: systolic $B P \geq 130$ or diastolic $B P \geq 85 \mathrm{~mm} \mathrm{Hg}$ or treatment of previously diagnosed hypertension

- raised fasting plasma glucose $\geq 1.00 \mathrm{~g} / \mathrm{I}(5.6 \mathrm{mmol} / \mathrm{l})$ or previously diagnosed type 2 diabetes.

American Heart Association/National Heart, Lung and Blood Institute (AHA/NHLBI) diagnostic criteria for Metabolic Syndrome $2005[17,18]$

Three or more of the following risk factors:

- Elevated waist circumference: $\geq 102 / 88 \mathrm{~cm}$ (men / women)

- Elevated triglycerides $\geq 1.50 \mathrm{~g} / \mathrm{l}(1.7 \mathrm{mmol} / \mathrm{l})$ or drug treatment for elevated triglycerides

- Reduced HDL-cholesterol < $0.40 / 0.50 \mathrm{~g} / \mathrm{l}(1.04 / 1.29 \mathrm{mmol} / \mathrm{l})$ (men/women) or drug treatment for reduced HDL-cholesterol (there is an incorrect conversion from $\mathrm{mg} / \mathrm{dl}$ to $\mathrm{mmol} / \mathrm{l}$, and the correction conversion is $1.03 / 1.29 \mathrm{mmol} / \mathrm{l}$ )

- Elevated blood pressure $\geq 130$ or $\geq 85 \mathrm{mmHg}$ or drug treatment for hypertension

- Elevated fasting glucose $\geq 1.00 \mathrm{~g} / \mathrm{l}(5.6 \mathrm{mmol} / \mathrm{l})$ or drug treatment for elevated glucose 


\section{TO BE PUT ONTO A WEB SITE}

Distribution of the centiles, means and standard deviations, according to age, of parameters included in the metabolic syndrome. Population is 130,882 consultants, 65,372 men and 65,510 women, examined in 2002-2004 at the "Institut inter Régional de la Santé", (IRSA) an Institute in central-western France which provides health examinations financed by the French social security system. The last column shows the reference values for a population aged 20-74 years with the same age structure as the French population according to the 1999 census. 
Waist circumference $(\mathrm{cm})$ : centiles by age class on 65,372 men from preventive health centers (IRSA, France)

\begin{tabular}{|c|c|c|c|c|c|c|c|c|c|c|c|c|c|}
\hline & & \multicolumn{10}{|c|}{ Ago (yoars) } & \multirow[b]{2}{*}{$70-74$} & \multirow[b]{2}{*}{$20-74$ " } \\
\hline & & $20-24$ & $25-29$ & $30-34$ & $35-39$ & $40-44$ & $45-49$ & $50-54$ & $55-59$ & $60-64$ & $65-69$ & & \\
\hline \multirow{3}{*}{\multicolumn{2}{|c|}{$\begin{array}{l}\text { n } \\
\text { mean } \\
\text { standard deviation }\end{array}$}} & 3,436 & 4,812 & 7,068 & 8,850 & 8,885 & 9,077 & 9,038 & 6,474 & 3,649 & 2,684 & 1,399 & 19,126 \\
\hline & & 79.2 & 83.2 & 85.8 & 87.5 & 89.3 & 90.9 & 92.7 & 94.0 & 94.6 & 96.0 & 97.4 & 89.1 \\
\hline & & 9.2 & 9.5 & 9.7 & 9.7 & 9.8 & 10.0 & 10.1 & 10.3 & 10.0 & 10.4 & 10.3 & 11.1 \\
\hline \multirow{21}{*}{ centiles } & 99 & 110 & 112 & 114 & 115 & 116 & 119 & 122 & 122 & 121 & 121 & 123 & 118 \\
\hline & 95 & 97 & 101 & 103 & 105 & 107 & 108 & 110 & 112 & 112 & 113 & 115 & 108 \\
\hline & 90 & 91 & 96 & 98 & 100 & 102 & 104 & 105 & 107 & 107 & 109 & 110 & 104 \\
\hline & 85 & 88 & 92 & 95 & 97 & 99 & 101 & 103 & 104 & 105 & 106 & 108 & 100 \\
\hline & 80 & 85 & 90 & 93 & 95 & 97 & 98 & 100 & 102 & 103 & 104 & 106 & 98 \\
\hline & 75 & 83 & 88 & 91 & 93 & 95 & 97 & 99 & 100 & 101 & 103 & 104 & 96 \\
\hline & 70 & 82 & 87 & 90 & 92 & 93 & 95 & 97 & 99 & 99 & 101 & 102 & 94 \\
\hline & 65 & 81 & 85 & 88 & 90 & 92 & 94 & 96 & 97 & 98 & 100 & 101 & 93 \\
\hline & 60 & 80 & 84 & 87 & 89 & 91 & 93 & 94 & 96 & 97 & 98 & 100 & 91 \\
\hline & 55 & 78 & 83 & 86 & 88 & 90 & 91 & 93 & 95 & 95 & 97 & 98 & 90 \\
\hline & 50 & 78 & 82 & 85 & 87 & 89 & 90 & 92 & 93 & 94 & 96 & 97 & 88 \\
\hline & 45 & 77 & 81 & 84 & 85 & 87 & 89 & 91 & 92 & 93 & 95 & 96 & 87 \\
\hline & 40 & 76 & 80 & 83 & 84 & 86 & 88 & 90 & 91 & 92 & 93 & 94 & 86 \\
\hline & 35 & 75 & 79 & 82 & 83 & 85 & 87 & 89 & 90 & 90 & 92 & 93 & 84 \\
\hline & 30 & 74 & 78 & 80 & 82 & 84 & 85 & 87 & 88 & 89 & 91 & 92 & 83 \\
\hline & 25 & 73 & 77 & 79 & 81 & 83 & 84 & 86 & 87 & 88 & 89 & 90 & 81 \\
\hline & 20 & 72 & 75 & 78 & 79 & 81 & 83 & 84 & 85 & 86 & 88 & 89 & 80 \\
\hline & 15 & 71 & 74 & 76 & 78 & 80 & 81 & 83 & 84 & 85 & 86 & 87 & 78 \\
\hline & 10 & 70 & 72 & 75 & 76 & 78 & 79 & 80 & 82 & 82 & 83 & 84 & 75 \\
\hline & 5 & 68 & 70 & 72 & 73 & 75 & 76 & 77 & 78 & 79 & 79 & 81 & 72 \\
\hline & 1 & 64 & 66 & 67 & 69 & 70 & 70 & 72 & 72 & 72 & 72 & 74 & 68 \\
\hline
\end{tabular}

" population with the same age structure as the French men 1999 census population aged 20-74.

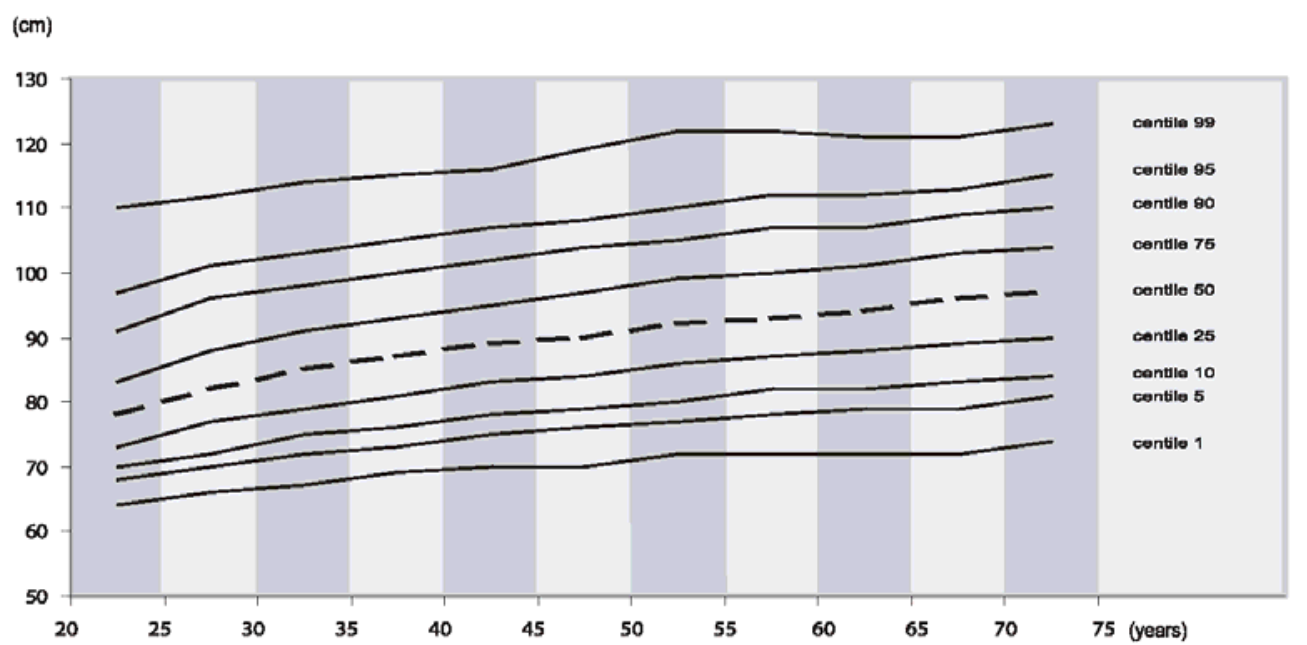


Waist circumference $(\mathrm{cm})$ : centiles by age class on 65,510 women from preventive health centers (IRSA, France)

\begin{tabular}{|c|c|c|c|c|c|c|c|c|c|c|c|c|c|}
\hline & & \multicolumn{10}{|c|}{ Age (years) } & \multirow[b]{2}{*}{$70-74$} & \multirow[b]{2}{*}{$20-74$ * } \\
\hline & & $20-24$ & $25-29$ & $30-34$ & $35-39$ & $40-44$ & $45-49$ & $50-54$ & $55-59$ & $60-64$ & $65-69$ & & \\
\hline \multicolumn{2}{|l|}{ n } & 5,261 & 5,398 & 7,264 & 7,368 & 8,558 & 8,879 & 8,619 & 6,655 & 3,509 & 2,580 & 1,419 & 19,874 \\
\hline \multicolumn{2}{|l|}{ mean } & 72.4 & 74.2 & 75.6 & 76.7 & 77.6 & 79.3 & 80.9 & 82.8 & 83.7 & 84.7 & 86.3 & 78.9 \\
\hline \multicolumn{2}{|c|}{ standard deviation } & 9.9 & 10.6 & 11.0 & 10.9 & 11.2 & 11.9 & 12.0 & 12.1 & 11.9 & 11.6 & 11.8 & 12.0 \\
\hline \multirow{21}{*}{ centiles } & 99 & 107 & 111 & 115 & 114 & 114 & 116 & 117 & 117 & 116 & 115 & 118 & 114 \\
\hline & 95 & 92 & 95 & 98 & 98 & 99 & 103 & 104 & 106 & 106 & 105 & 107 & 102 \\
\hline & 90 & 85 & 88 & 90 & 91 & 93 & 96 & 97 & 100 & 100 & 101 & 102 & 96 \\
\hline & 85 & 81 & 84 & 86 & 87 & 89 & 91 & 93 & 95 & 96 & 97 & 98 & 92 \\
\hline & 80 & 78 & 81 & 83 & 84 & 86 & 88 & 90 & 92 & 93 & 94 & 96 & 88 \\
\hline & 75 & 77 & 78 & 80 & 82 & 83 & 85 & 88 & 90 & 91 & 92 & 94 & 86 \\
\hline & 70 & 75 & 77 & 78 & 80 & 81 & 83 & 85 & 88 & 89 & 90 & 92 & 84 \\
\hline & 65 & 73 & 76 & 77 & 78 & 79 & 81 & 84 & 86 & 87 & 88 & 91 & 82 \\
\hline & 60 & 72 & 74 & 75 & 77 & 78 & 80 & 82 & 84 & 85 & 87 & 89 & 80 \\
\hline & 55 & 71 & 73 & 74 & 75 & 76 & 78 & 80 & 82 & 84 & 85 & 87 & 78 \\
\hline & 50 & 70 & 72 & 73 & 74 & 75 & 77 & 79 & 81 & 82 & 84 & 86 & 76 \\
\hline & 45 & 69 & 71 & 72 & 73 & 74 & 75 & 77 & 79 & 81 & 82 & 84 & 75 \\
\hline & 40 & 68 & 70 & 71 & 72 & 73 & 74 & 76 & 78 & 79 & 81 & 83 & 74 \\
\hline & 35 & 68 & 69 & 70 & 71 & 72 & 73 & 75 & 77 & 78 & 80 & 81 & 72 \\
\hline & 30 & 67 & 68 & 69 & 70 & 71 & 72 & 73 & 75 & 76 & 78 & 80 & 71 \\
\hline & 25 & 66 & 67 & 68 & 69 & 70 & 71 & 72 & 74 & 75 & 76 & 77 & 70 \\
\hline & 20 & 65 & 66 & 67 & 68 & 69 & 70 & 71 & 72 & 73 & 74 & 76 & 69 \\
\hline & 15 & 64 & 65 & 66 & 67 & 67 & 68 & 69 & 71 & 72 & 73 & 73 & 67 \\
\hline & 10 & 63 & 64 & 65 & 66 & 66 & 67 & 68 & 69 & 70 & 71 & 72 & 66 \\
\hline & 5 & 61 & 62 & 63 & 64 & 64 & 64 & 65 & 66 & 67 & 68 & 68 & 64 \\
\hline & 1 & 58 & 58 & 60 & 60 & 61 & 61 & 62 & 62 & 63 & 63 & 62 & 60 \\
\hline
\end{tabular}

" population with the same age structure as the French women 1999 census population aged 20-74.

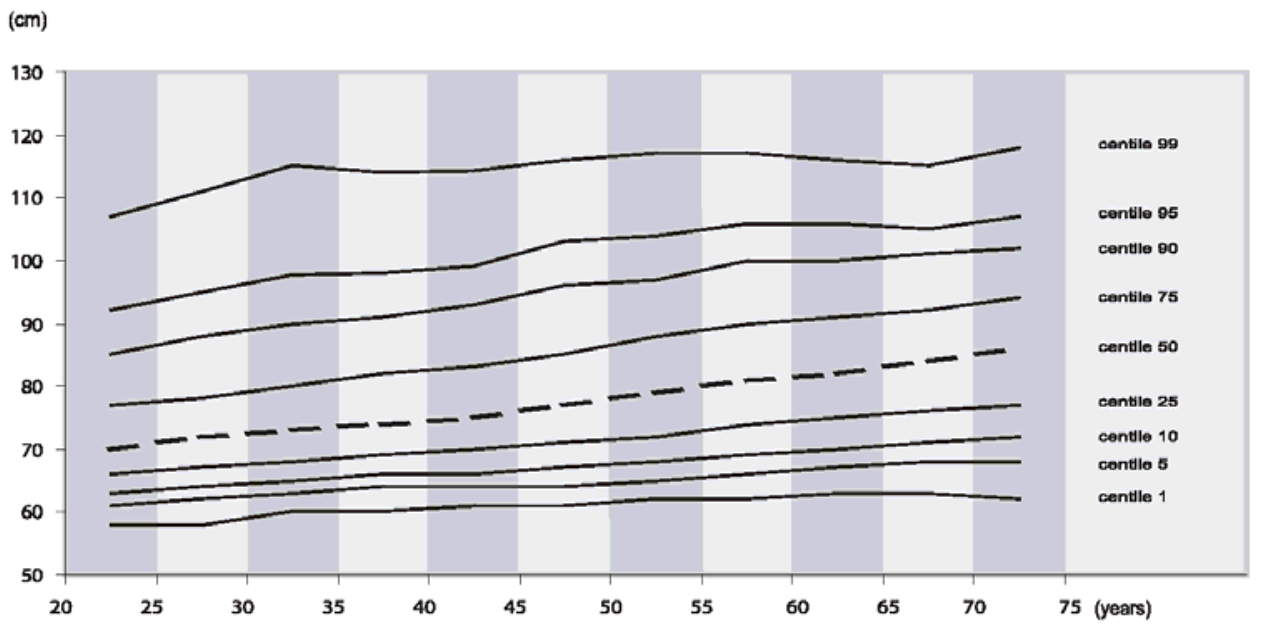


Glucose (g/l) : centiles by age class on 65,372 men from preventive health centers (IRSA, France)

\begin{tabular}{|c|c|c|c|c|c|c|c|c|c|c|c|c|c|}
\hline \multicolumn{14}{|c|}{ Age (years) } \\
\hline & & $20-24$ & $25-29$ & $30-34$ & $35-39$ & $40-44$ & $45-49$ & $50-54$ & $55-59$ & $60-64$ & $65-69$ & $70-74$ & $20-74$ \\
\hline \multicolumn{2}{|l|}{ n } & 3,436 & 4,812 & 7,068 & 8,850 & 8,885 & 9,077 & 9,038 & 6,474 & 3,649 & 2,684 & 1,399 & 19,126 \\
\hline \multicolumn{2}{|l|}{ mean } & 0.91 & 0.92 & 0.94 & 0.96 & 0.98 & 1.00 & 1.02 & 1.04 & 1.03 & 1.04 & 1.05 & 0.98 \\
\hline \multicolumn{2}{|c|}{ standard deviation } & 0.11 & 0.10 & 0.11 & 0.12 & 0.14 & 0.16 & 0.19 & 0.21 & 0.21 & 0.22 & 0.25 & 0.17 \\
\hline \multirow{21}{*}{ centiles } & 99 & 1.19 & 1.14 & 1.19 & 1.25 & 1.38 & 1.57 & 1.81 & 1.97 & 1.99 & 1.97 & 2.17 & 1.66 \\
\hline & 95 & 1.05 & 1.06 & 1.09 & 1.11 & 1.15 & 1.21 & 1.25 & 1.32 & 1.33 & 1.39 & 1.49 & 1.20 \\
\hline & 90 & 1.01 & 1.02 & 1.04 & 1.07 & 1.10 & 1.13 & 1.16 & 1.2 & 1.19 & 1.22 & 1.27 & 1.12 \\
\hline & 85 & 0.99 & 1.00 & 1.02 & 1.04 & 1.07 & 1.10 & 1.12 & 1.14 & 1.14 & 1.15 & 1.18 & 1.08 \\
\hline & 80 & 0.98 & 0.98 & 1.00 & 1.02 & 1.04 & 1.07 & 1.09 & 1.11 & 1.10 & 1.11 & 1.13 & 1.05 \\
\hline & 75 & 0.96 & 0.97 & 0.99 & 1.00 & 1.03 & 1.05 & 1.07 & 1.08 & 1.07 & 1.08 & 1.10 & 1.03 \\
\hline & 70 & 0.95 & 0.96 & 0.97 & 0.99 & 1.01 & 1.03 & 1.05 & 1.06 & 1.05 & 1.06 & 1.07 & 1.01 \\
\hline & 65 & 0.93 & 0.95 & 0.96 & 0.98 & 1.00 & 1.02 & 1.03 & 1.04 & 1.04 & 1.04 & 1.04 & 1.00 \\
\hline & 60 & 0.92 & 0.94 & 0.95 & 0.97 & 0.99 & 1.01 & 1.02 & 1.03 & 1.02 & 1.02 & 1.03 & 0.98 \\
\hline & 55 & 0.92 & 0.93 & 0.94 & 0.96 & 0.97 & 0.99 & 1.01 & 1.01 & 1.01 & 1.01 & 1.01 & 0.97 \\
\hline & 50 & 0.91 & 0.92 & 0.93 & 0.95 & 0.96 & 0.98 & 0.99 & 1.00 & 0.99 & 0.99 & 0.99 & 0.96 \\
\hline & 45 & 0.90 & 0.91 & 0.92 & 0.94 & 0.95 & 0.97 & 0.98 & 0.98 & 0.98 & 0.98 & 0.98 & 0.95 \\
\hline & 40 & 0.89 & 0.90 & 0.91 & 0.92 & 0.94 & 0.96 & 0.97 & 0.97 & 0.97 & 0.96 & 0.97 & 0.93 \\
\hline & 35 & 0.88 & 0.89 & 0.90 & 0.91 & 0.93 & 0.95 & 0.96 & 0.96 & 0.95 & 0.95 & 0.95 & 0.92 \\
\hline & 30 & 0.87 & 0.88 & 0.89 & 0.90 & 0.92 & 0.93 & 0.94 & 0.95 & 0.94 & 0.94 & 0.94 & 0.91 \\
\hline & 25 & 0.86 & 0.87 & 0.88 & 0.89 & 0.90 & 0.92 & 0.93 & 0.93 & 0.93 & 0.92 & 0.92 & 0.90 \\
\hline & 20 & 0.85 & 0.86 & 0.87 & 0.88 & 0.89 & 0.90 & 0.92 & 0.92 & 0.91 & 0.91 & 0.91 & 0.88 \\
\hline & 15 & 0.83 & 0.85 & 0.85 & 0.86 & 0.88 & 0.89 & 0.90 & 0.90 & 0.90 & 0.89 & 0.89 & 0.87 \\
\hline & 10 & 0.81 & 0.83 & 0.83 & 0.84 & 0.86 & 0.87 & 0.88 & 0.88 & 0.88 & 0.87 & 0.87 & 0.85 \\
\hline & 5 & 0.79 & 0.80 & 0.81 & 0.82 & 0.83 & 0.84 & 0.85 & 0.85 & 0.85 & 0.85 & 0.85 & 0.82 \\
\hline & 1 & 0.72 & 0.74 & 0.74 & 0.76 & 0.77 & 0.78 & 0.79 & 0.79 & 0.79 & 0.79 & 0.80 & 0.76 \\
\hline
\end{tabular}

" population with the same age structure as the French men 1999 census population aged 20-74.

(gii)

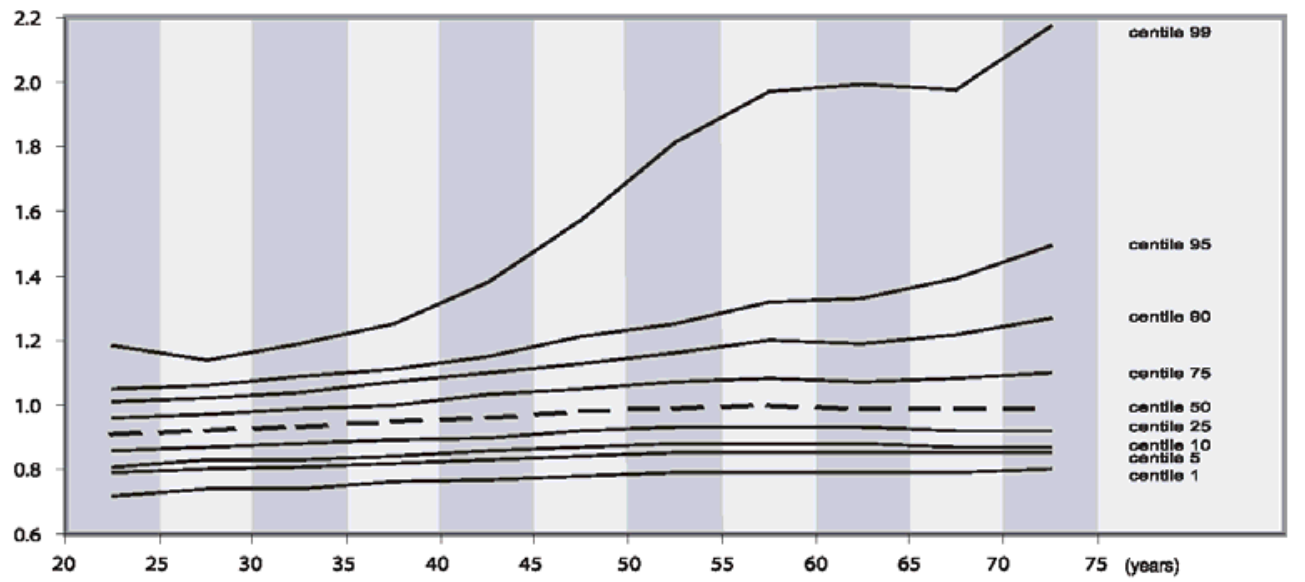


Glucose $(g / I)$ : centiles by age class on 65,510 women from preventive health centers (IRSA, France)

\begin{tabular}{|c|c|c|c|c|c|c|c|c|c|c|c|c|c|}
\hline \multicolumn{14}{|c|}{ Age (years) } \\
\hline & & $20-24$ & $25-29$ & 30-34 & $35-39$ & $40-44$ & $45-49$ & $50-54$ & $55-59$ & $60-64$ & $65-69$ & $70-74$ & $20-74 *$ \\
\hline \multicolumn{2}{|l|}{ n } & 5,261 & 5,398 & 7,264 & 7,368 & 8,558 & 8,879 & 8,619 & 6,655 & 3,509 & 2,580 & 1,419 & 19,874 \\
\hline \multicolumn{2}{|l|}{ mean } & 0.87 & 0.87 & 0.89 & 0.90 & 0.92 & 0.94 & 0.95 & 0.96 & 0.97 & 0.97 & 0.99 & 0.93 \\
\hline \multicolumn{2}{|c|}{ standard deviation } & 0.10 & 0.10 & 0.10 & 0.11 & 0.12 & 0.15 & 0.15 & 0.16 & 0.17 & 0.19 & 0.20 & 0.15 \\
\hline \multirow{21}{*}{ centiles } & 99 & 1.07 & 1.10 & 1.12 & 1.17 & 1.26 & 1.35 & 1.44 & 1.60 & 1.63 & 1.77 & 1.93 & 1.43 \\
\hline & 95 & 0.99 & 1.00 & 1.02 & 1.04 & 1.08 & 1.11 & 1.14 & 1.17 & 1.20 & 1.22 & 1.33 & 1.11 \\
\hline & 90 & 0.96 & 0.97 & 0.98 & 1.00 & 1.03 & 1.05 & 1.07 & 1.09 & 1.10 & 1.11 & 1.16 & 1.04 \\
\hline & 85 & 0.94 & 0.95 & 0.96 & 0.98 & 1.00 & 1.02 & 1.04 & 1.05 & 1.06 & 1.06 & 1.08 & 1.01 \\
\hline & 80 & 0.92 & 0.93 & 0.94 & 0.96 & 0.98 & 1.00 & 1.01 & 1.02 & 1.03 & 1.03 & 1.06 & 0.99 \\
\hline & 75 & 0.91 & 0.92 & 0.93 & 0.94 & 0.96 & 0.98 & 1.00 & 1.00 & 1.01 & 1.01 & 1.03 & 0.97 \\
\hline & 70 & 0.90 & 0.91 & 0.92 & 0.93 & 0.95 & 0.97 & 0.98 & 0.99 & 0.99 & 0.99 & 1.01 & 0.95 \\
\hline & 65 & 0.89 & 0.89 & 0.91 & 0.92 & 0.94 & 0.95 & 0.96 & 0.97 & 0.97 & 0.98 & 0.99 & 0.94 \\
\hline & 60 & 0.88 & 0.89 & 0.90 & 0.91 & 0.93 & 0.94 & 0.95 & 0.96 & 0.96 & 0.96 & 0.97 & 0.93 \\
\hline & 55 & 0.87 & 0.88 & 0.89 & 0.9 & 0.92 & 0.93 & 0.94 & 0.95 & 0.95 & 0.95 & 0.96 & 0.92 \\
\hline & 50 & 0.86 & 0.87 & 0.88 & 0.89 & 0.91 & 0.92 & 0.93 & 0.94 & 0.94 & 0.94 & 0.95 & 0.90 \\
\hline & 45 & 0.85 & 0.86 & 0.87 & 0.88 & 0.90 & 0.91 & 0.92 & 0.92 & 0.92 & 0.93 & 0.94 & 0.89 \\
\hline & 40 & 0.84 & 0.85 & 0.86 & 0.87 & 0.89 & 0.90 & 0.91 & 0.91 & 0.91 & 0.92 & 0.93 & 0.88 \\
\hline & 35 & 0.84 & 0.84 & 0.85 & 0.86 & 0.88 & 0.89 & 0.90 & 0.90 & 0.90 & 0.91 & 0.91 & 0.87 \\
\hline & 30 & 0.83 & 0.83 & 0.84 & 0.85 & 0.87 & 0.88 & 0.89 & 0.89 & 0.89 & 0.90 & 0.90 & 0.86 \\
\hline & 25 & 0.82 & 0.83 & 0.83 & 0.84 & 0.86 & 0.87 & 0.87 & 0.88 & 0.88 & 0.88 & 0.89 & 0.85 \\
\hline & 20 & 0.80 & 0.81 & 0.82 & 0.83 & 0.84 & 0.86 & 0.86 & 0.87 & 0.87 & 0.87 & 0.87 & 0.84 \\
\hline & 15 & 0.79 & 0.80 & 0.81 & 0.82 & 0.83 & 0.84 & 0.85 & 0.85 & 0.85 & 0.85 & 0.86 & 0.83 \\
\hline & 10 & 0.78 & 0.78 & 0.79 & 0.8 & 0.81 & 0.83 & 0.83 & 0.83 & 0.84 & 0.84 & 0.84 & 0.81 \\
\hline & 5 & 0.75 & 0.76 & 0.77 & 0.78 & 0.79 & 0.80 & 0.80 & 0.80 & 0.81 & 0.81 & 0.80 & 0.78 \\
\hline & 1 & 0.71 & 0.71 & 0.72 & 0.74 & 0.74 & 0.74 & 0.75 & 0.76 & 0.75 & 0.76 & 0.76 & 0.73 \\
\hline
\end{tabular}

${ }^{*}$ population with the same age structure as the French women 1999 census population aged 20-74.

(gni)

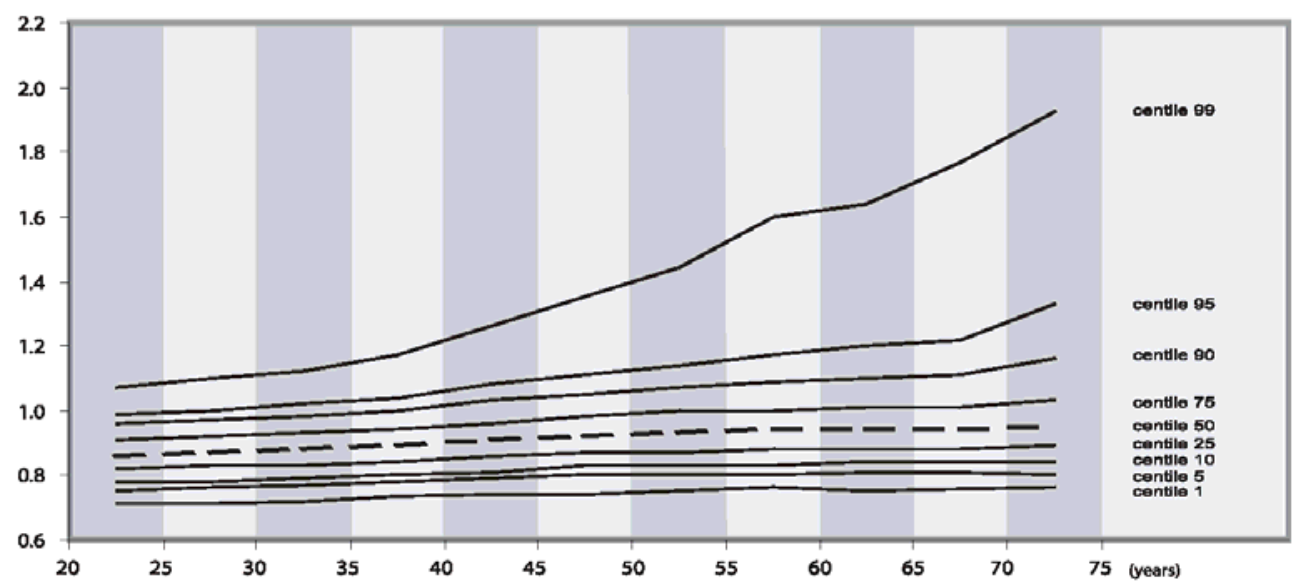


Triglycerides $(g / l)$ : centiles by age class on 65,372 men from preventive health centers (IRSA, France)

\begin{tabular}{|c|c|c|c|c|c|c|c|c|c|c|c|c|c|}
\hline \multicolumn{14}{|c|}{ Age (years) } \\
\hline & & $20-24$ & $25-29$ & $30-34$ & $35-39$ & $40-44$ & $45-49$ & $50-54$ & $55-59$ & $60-64$ & $65-69$ & $70-74$ & $20-74$ * \\
\hline \multicolumn{2}{|l|}{$n$} & 3,436 & 4,812 & 7,068 & 8,850 & 8,885 & 9,077 & 9,038 & 6,474 & 3,649 & 2,684 & 1,399 & 19,126 \\
\hline \multicolumn{2}{|l|}{ mean } & 0.84 & 0.93 & 1.01 & 1.06 & 1.11 & 1.14 & 1.15 & 1.14 & 1.12 & 1.09 & 1.10 & 1.06 \\
\hline \multicolumn{2}{|c|}{ standard deviation } & 0.47 & 0.56 & 0.64 & 0.63 & 0.67 & 0.66 & 0.66 & 0.65 & 0.59 & 0.53 & 0.53 & 0.62 \\
\hline \multirow{21}{*}{ centiles } & 99 & 2.62 & 3.11 & 3.38 & 3.26 & 3.53 & 3.51 & 3.53 & 3.35 & 3.20 & 3.06 & 3.12 & 3.28 \\
\hline & 95 & 1.72 & 2.01 & 2.20 & 2.32 & 2.44 & 2.45 & 2.47 & 2.36 & 2.20 & 2.06 & 2.20 & 2.26 \\
\hline & 90 & 1.39 & 1.56 & 1.73 & 1.86 & 1.92 & 1.99 & 1.98 & 1.90 & 1.83 & 1.78 & 1.75 & 1.81 \\
\hline & 85 & 1.19 & 1.34 & 1.49 & 1.58 & 1.67 & 1.71 & 1.70 & 1.66 & 1.62 & 1.57 & 1.56 & 1.57 \\
\hline & 80 & 1.09 & 1.21 & 1.33 & 1.41 & 1.49 & 1.53 & 1.53 & 1.49 & 1.48 & 1.44 & 1.41 & 1.40 \\
\hline & 75 & 1,00 & 1.10 & 1.21 & 1.28 & 1.34 & 1.39 & 1.38 & 1.36 & 1.37 & 1.32 & 1.30 & 1.27 \\
\hline & 70 & 0.92 & 1.02 & 1.11 & 1.18 & 1.23 & 1.28 & 1.28 & 1.27 & 1.26 & 1.24 & 1.20 & 1.17 \\
\hline & 65 & 0.86 & 0.95 & 1.02 & 1.09 & 1.14 & 1.18 & 1.18 & 1.18 & 1.18 & 1.16 & 1.14 & 1.09 \\
\hline & 60 & 0.80 & 0.88 & 0.95 & 1.01 & 1.07 & 1.09 & 1.10 & 1.10 & 1.10 & 1.08 & 1.09 & 1.02 \\
\hline & 55 & 0.76 & 0.83 & 0.88 & 0.94 & 0.99 & 1.02 & 1.04 & 1.04 & 1.04 & 1.02 & 1.01 & 0.96 \\
\hline & 50 & 0.72 & 0.78 & 0.83 & 0.89 & 0.93 & 0.96 & 0.97 & 0.98 & 0.98 & 0.97 & 0.96 & 0.90 \\
\hline & 45 & 0.68 & 0.73 & 0.78 & 0.83 & 0.87 & 0.90 & 0.91 & 0.92 & 0.92 & 0.92 & 0.92 & 0.84 \\
\hline & 40 & 0.65 & 0.69 & 0.73 & 0.78 & 0.82 & 0.85 & 0.86 & 0.87 & 0.87 & 0.87 & 0.87 & 0.79 \\
\hline & 35 & 0.61 & 0.65 & 0.69 & 0.73 & 0.76 & 0.80 & 0.80 & 0.82 & 0.82 & 0.82 & 0.82 & 0.74 \\
\hline & 30 & 0.58 & 0.61 & 0.65 & 0.68 & 0.72 & 0.75 & 0.76 & 0.77 & 0.78 & 0.76 & 0.78 & 0.70 \\
\hline & 25 & 0.55 & 0.57 & 0.61 & 0.64 & 0.67 & 0.70 & 0.71 & 0.72 & 0.73 & 0.72 & 0.73 & 0.65 \\
\hline & 20 & 0.51 & 0.53 & 0.57 & 0.60 & 0.63 & 0.65 & 0.66 & 0.67 & 0.69 & 0.68 & 0.69 & 0.61 \\
\hline & 15 & 0.47 & 0.49 & 0.52 & 0.55 & 0.57 & 0.60 & 0.61 & 0.62 & 0.63 & 0.63 & 0.65 & 0.56 \\
\hline & 10 & 0.43 & 0.45 & 0.47 & 0.50 & 0.52 & 0.54 & 0.55 & 0.56 & 0.58 & 0.58 & 0.60 & 0.51 \\
\hline & 5 & 0.38 & 0.38 & 0.41 & 0.44 & 0.45 & 0.47 & 0.48 & 0.49 & 0.50 & 0.50 & 0.53 & 0.44 \\
\hline & 1 & 0.30 & 0.30 & 0.33 & 0.33 & 0.36 & 0.37 & 0.37 & 0.38 & 0.40 & 0.40 & 0.41 & 0.34 \\
\hline
\end{tabular}

* population with the same age structure as the French men 1999 census population aged 20-74.

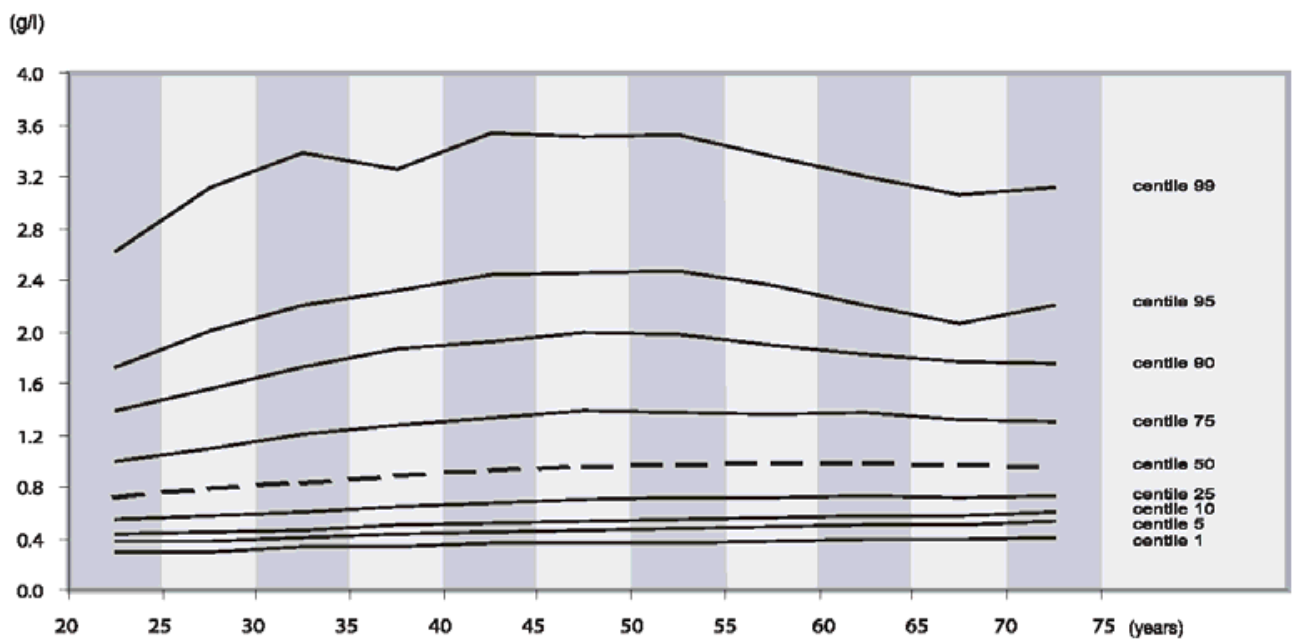


Triglycerides $(\mathrm{g} / \mathrm{l})$ : centiles by age class on 65,510 women from preventive health centers (IRSA, France)

\begin{tabular}{|c|c|c|c|c|c|c|c|c|c|c|c|c|c|}
\hline \multicolumn{14}{|c|}{ Age (years) } \\
\hline & & $20-24$ & $25-29$ & $30-34$ & $35-39$ & $40-44$ & $45-49$ & $50-54$ & $55-59$ & $60-64$ & $65-69$ & $70-74$ & $20-74$ " \\
\hline \multicolumn{2}{|l|}{$\mathbf{n}$} & 5,261 & 5,398 & 7,264 & 7,368 & 8,558 & 8,879 & 8,619 & 6,655 & 3,509 & 2,580 & 1,419 & 19,874 \\
\hline \multicolumn{2}{|l|}{ mean } & 0.83 & 0.80 & 0.79 & 0.78 & 0.79 & 0.82 & 0.85 & 0.93 & 0.97 & 0.98 & 1.02 & 0.85 \\
\hline \multicolumn{2}{|c|}{ standard devlation } & 0.36 & 0.38 & 0.38 & 0.39 & 0.40 & 0.45 & 0.44 & 0.47 & 0.48 & 0.46 & 0.51 & 0.43 \\
\hline \multirow{21}{*}{ centiles } & 99 & 2.09 & 2.12 & 2.15 & 2.20 & 2.26 & 2.37 & 2.49 & 2.64 & 2.67 & 2.53 & 2.88 & 2.41 \\
\hline & 95 & 1.50 & 1.51 & 1.50 & 1.48 & 1.52 & 1.62 & 1.67 & 1.83 & 1.89 & 1.88 & 1.93 & 1.65 \\
\hline & 90 & 1.29 & 1.27 & 1.25 & 1.23 & 1.26 & 1.31 & 1.37 & 1.50 & 1.55 & 1.54 & 1.61 & 1.35 \\
\hline & 85 & 1.18 & 1.14 & 1.10 & 1.09 & 1.11 & 1.15 & 1.20 & 1.31 & 1.37 & 1.39 & 1.41 & 1.21 \\
\hline & 80 & 1.07 & 1.03 & 1.01 & 1.00 & 1.01 & 1.04 & 1.09 & 1.19 & 1.24 & 1.26 & 1.29 & 1.10 \\
\hline & 75 & 1.00 & 0.96 & 0.94 & 0.93 & 0.93 & 0.96 & 1.01 & 1.09 & 1.14 & 1.16 & 1.20 & 1.02 \\
\hline & 70 & 0.94 & 0.90 & 0.87 & 0.86 & 0.86 & 0.89 & 0.93 & 1.02 & 1.07 & 1.09 & 1.12 & 0.95 \\
\hline & 65 & 0.88 & 0.84 & 0.83 & 0.81 & 0.81 & 0.83 & 0.87 & 0.96 & 1.01 & 1.03 & 1.06 & 0.89 \\
\hline & 60 & 0.83 & 0.80 & 0.78 & 0.77 & 0.77 & 0.79 & 0.82 & 0.90 & 0.95 & 0.97 & 1.01 & 0.84 \\
\hline & 55 & 0.79 & 0.75 & 0.74 & 0.73 & 0.73 & 0.74 & 0.78 & 0.85 & 0.89 & 0.91 & 0.96 & 0.79 \\
\hline & 50 & 0.75 & 0.71 & 0.69 & 0.68 & 0.69 & 0.71 & 0.74 & 0.80 & 0.85 & 0.87 & 0.91 & 0.75 \\
\hline & 45 & 0.72 & 0.68 & 0.66 & 0.65 & 0.65 & 0.67 & 0.70 & 0.76 & 0.81 & 0.83 & 0.86 & 0.71 \\
\hline & 40 & 0.68 & 0.64 & 0.63 & 0.61 & 0.62 & 0.64 & 0.67 & 0.72 & 0.76 & 0.79 & 0.82 & 0.67 \\
\hline & 35 & 0.65 & 0.61 & 0.60 & 0.58 & 0.59 & 0.61 & 0.63 & 0.68 & 0.72 & 0.75 & 0.77 & 0.64 \\
\hline & 30 & 0.62 & 0.58 & 0.56 & 0.55 & 0.56 & 0.58 & 0.60 & 0.65 & 0.68 & 0.70 & 0.72 & 0.60 \\
\hline & 25 & 0.58 & 0.54 & 0.53 & 0.52 & 0.53 & 0.55 & 0.57 & 0.62 & 0.65 & 0.66 & 0.68 & 0.57 \\
\hline & 20 & 0.55 & 0.51 & 0.50 & 0.49 & 0.50 & 0.52 & 0.53 & 0.58 & 0.61 & 0.62 & 0.65 & 0.54 \\
\hline & 15 & 0.50 & 0.47 & 0.46 & 0.46 & 0.47 & 0.48 & 0.5 & 0.54 & 0.57 & 0.57 & 0.6 & 0.50 \\
\hline & 10 & 0.46 & 0.43 & 0.43 & 0.42 & 0.43 & 0.44 & 0.46 & 0.50 & 0.52 & 0.53 & 0.55 & 0.46 \\
\hline & 5 & 0.40 & 0.38 & 0.38 & 0.38 & 0.39 & 0.40 & 0.42 & 0.45 & 0.45 & 0.47 & 0.49 & 0.40 \\
\hline & 1 & 0.31 & 0.30 & 0.30 & 0.31 & 0.31 & 0.33 & 0.34 & 0.36 & 0.38 & 0.39 & 0.41 & 0.32 \\
\hline
\end{tabular}

* population with the same age structure as the French women 1999 census population aged 20-74.

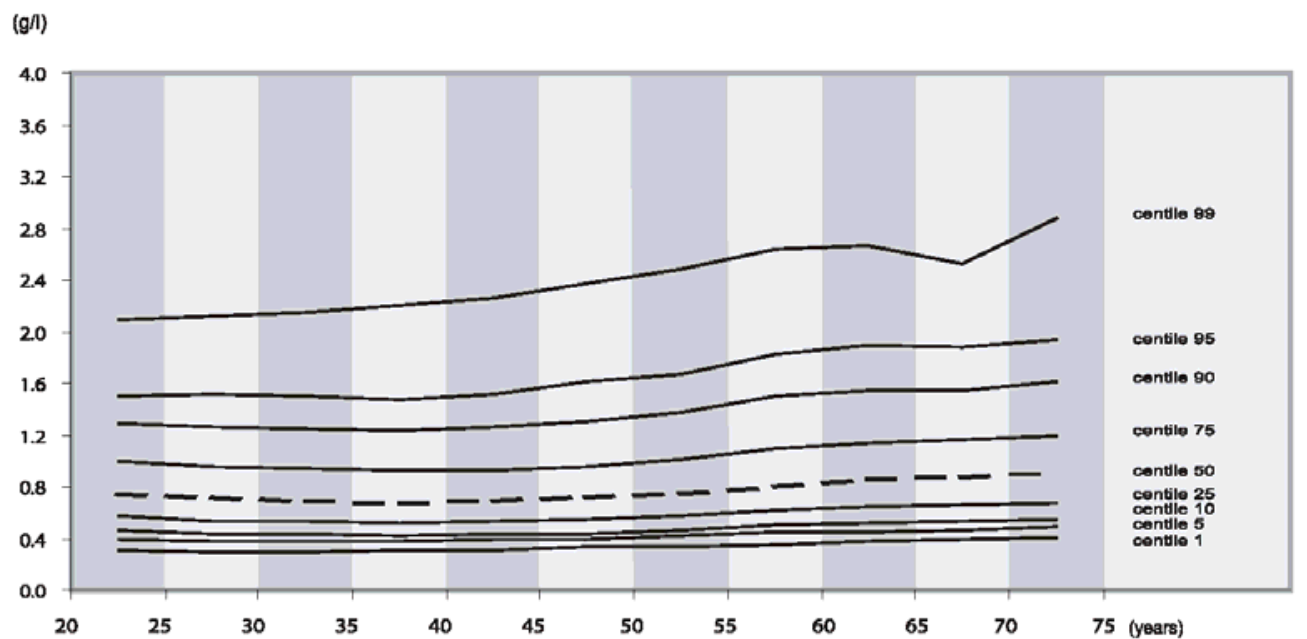


HDL-Cholesterol ( $g / l)$ : centiles by age class on 65,372 men from preventive health centers (IRSA, France)

\begin{tabular}{|c|c|c|c|c|c|c|c|c|c|c|c|c|c|}
\hline \multicolumn{14}{|c|}{ Age (years) } \\
\hline & & $20-24$ & $25-29$ & 30-34 & $35-39$ & $40-44$ & $45-49$ & $50-54$ & $55-59$ & $60-64$ & $65-69$ & $70-74$ & $20-74 *$ \\
\hline \multicolumn{2}{|l|}{ n } & 3,436 & 4,812 & 7,068 & 8,850 & $\mathbf{8 , 8 8 5}$ & 9,077 & 9,038 & 6,474 & 3,649 & 2,684 & 1,399 & 19,126 \\
\hline \multicolumn{2}{|l|}{ mean } & 0.51 & 0.53 & 0.53 & 0.54 & 0.55 & 0.56 & 0.56 & 0.56 & 0.56 & 0.56 & 0.56 & 0.55 \\
\hline \multicolumn{2}{|c|}{ standard deviation } & 0.12 & 0.13 & 0.13 & 0.13 & 0.14 & 0.14 & 0.14 & 0.13 & 0.14 & 0.13 & 0.14 & 0.13 \\
\hline \multirow{21}{*}{ centiles } & 99 & 0.85 & 0.90 & 0.91 & 0.95 & 0.98 & 0.99 & 0.98 & 0.95 & 0.98 & 0.97 & 1,00 & 0.95 \\
\hline & 95 & 0.72 & 0.77 & 0.77 & 0.79 & 0.80 & 0.81 & 0.81 & 0.80 & 0.81 & 0.80 & 0.83 & 0.79 \\
\hline & 90 & 0.66 & 0.70 & 0.70 & 0.72 & 0.73 & 0.73 & 0.74 & 0.73 & 0.74 & 0.73 & 0.74 & 0.72 \\
\hline & 85 & 0.63 & 0.66 & 0.65 & 0.67 & 0.69 & 0.69 & 0.69 & 0.69 & 0.69 & 0.69 & 0.70 & 0.68 \\
\hline & 80 & 0.60 & 0.62 & 0.63 & 0.64 & 0.65 & 0.66 & 0.66 & 0.66 & 0.66 & 0.66 & 0.66 & 0.64 \\
\hline & 75 & 0.58 & 0.60 & 0.60 & 0.62 & 0.63 & 0.63 & 0.63 & 0.63 & 0.63 & 0.63 & 0.63 & 0.62 \\
\hline & 70 & 0.56 & 0.58 & 0.58 & 0.59 & 0.60 & 0.61 & 0.61 & 0.61 & 0.61 & 0.61 & 0.61 & 0.60 \\
\hline & 65 & 0.54 & 0.56 & 0.56 & 0.57 & 0.58 & 0.59 & 0.59 & 0.59 & 0.59 & 0.59 & 0.59 & 0.58 \\
\hline & 60 & 0.53 & 0.54 & 0.54 & 0.56 & 0.57 & 0.57 & 0.57 & 0.57 & 0.57 & 0.57 & 0.57 & 0.56 \\
\hline & 55 & 0.51 & 0.53 & 0.53 & 0.54 & 0.55 & 0.55 & 0.55 & 0.55 & 0.55 & 0.55 & 0.56 & 0.54 \\
\hline & 50 & 0.50 & 0.51 & 0.51 & 0.52 & 0.53 & 0.53 & 0.54 & 0.54 & 0.54 & 0.54 & 0.54 & 0.53 \\
\hline & 45 & 0.48 & 0.50 & 0.50 & 0.51 & 0.52 & 0.52 & 0.52 & 0.52 & 0.53 & 0.53 & 0.52 & 0.51 \\
\hline & 40 & 0.47 & 0.48 & 0.48 & 0.49 & 0.50 & 0.50 & 0.51 & 0.51 & 0.51 & 0.51 & 0.51 & 0.50 \\
\hline & 35 & 0.46 & 0.47 & 0.47 & 0.48 & 0.49 & 0.49 & 0.49 & 0.49 & 0.50 & 0.50 & 0.49 & 0.48 \\
\hline & 30 & 0.44 & 0.45 & 0.46 & 0.47 & 0.47 & 0.47 & 0.48 & 0.48 & 0.48 & 0.48 & 0.48 & 0.47 \\
\hline & 25 & 0.43 & 0.44 & 0.44 & 0.45 & 0.46 & 0.46 & 0.46 & 0.46 & 0.47 & 0.47 & 0.46 & 0.45 \\
\hline & 20 & 0.41 & 0.42 & 0.43 & 0.43 & 0.44 & 0.44 & 0.44 & 0.45 & 0.45 & 0.45 & 0.45 & 0.44 \\
\hline & 15 & 0.40 & 0.40 & 0.41 & 0.42 & 0.42 & 0.43 & 0.43 & 0.43 & 0.43 & 0.43 & 0.42 & 0.42 \\
\hline & 10 & 0.38 & 0.39 & 0.39 & 0.40 & 0.40 & 0.40 & 0.40 & 0.41 & 0.41 & 0.40 & 0.40 & 0.40 \\
\hline & 5 & 0.35 & 0.36 & 0.36 & 0.37 & 0.37 & 0.37 & 0.37 & 0.37 & 0.37 & 0.37 & 0.37 & 0.37 \\
\hline & 1 & 0.30 & 0.31 & 0.30 & 0.32 & 0.32 & 0.31 & 0.32 & 0.32 & 0.32 & 0.32 & 0.32 & 0.31 \\
\hline
\end{tabular}

" population with the same age structure as the French men 1999 census population aged 20-74.

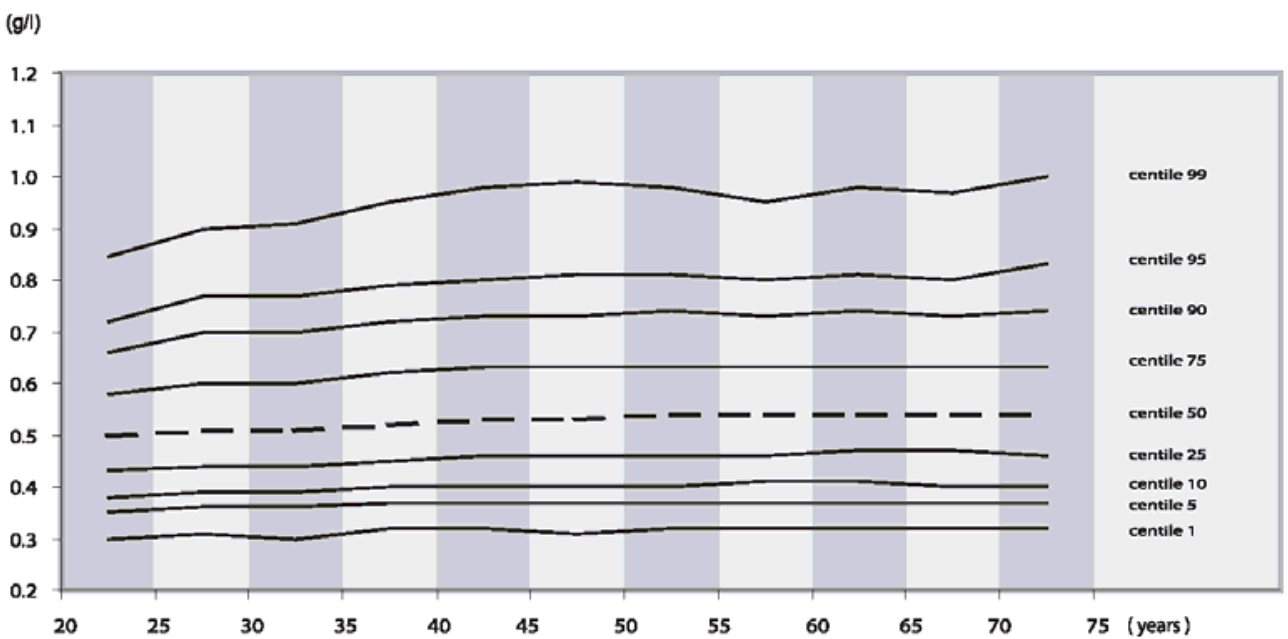


HDL-Cholesterol (g/l) : centiles by age class on 65,510 women from preventive health centers (IRSA, France)

\begin{tabular}{|c|c|c|c|c|c|c|c|c|c|c|c|c|c|}
\hline \multicolumn{14}{|c|}{ Age (years) } \\
\hline & & $20-24$ & 25-29 & $30-34$ & $35-39$ & $40-44$ & $45-49$ & $50-54$ & $55-59$ & $60-64$ & $65-69$ & $70-74$ & $20-74$ \\
\hline \multicolumn{2}{|l|}{$n$} & 5,261 & 5,398 & 7,264 & 7,368 & 8,558 & 8,879 & 8,619 & 6,655 & 3,509 & 2,580 & 1,419 & 19,874 \\
\hline \multicolumn{2}{|l|}{ mean } & 0.59 & 0.61 & 0.61 & 0.63 & 0.64 & 0.65 & 0.67 & 0.67 & 0.67 & 0.67 & 0.66 & 0.64 \\
\hline \multicolumn{2}{|c|}{ standard deviation } & 0.14 & 0.15 & 0.14 & 0.15 & 0.15 & 0.15 & 0.16 & 0.16 & 0.16 & 0.16 & 0.16 & 0.15 \\
\hline \multirow{21}{*}{ centiles } & 99 & 0.97 & 1.03 & 1.01 & 1.03 & 1.04 & 1.06 & 1.13 & 1.12 & 1.12 & 1.10 & 1.10 & 1.07 \\
\hline & 95 & 0.84 & 0.88 & 0.86 & 0.89 & 0.90 & 0.93 & 0.97 & 0.97 & 0.96 & 0.96 & 0.93 & 0.92 \\
\hline & 90 & 0.77 & 0.81 & 0.80 & 0.82 & 0.84 & 0.85 & 0.89 & 0.89 & 0.88 & 0.88 & 0.86 & 0.84 \\
\hline & 85 & 0.73 & 0.76 & 0.76 & 0.78 & 0.80 & 0.81 & 0.84 & 0.84 & 0.84 & 0.83 & 0.82 & 0.80 \\
\hline & 80 & 0.69 & 0.73 & 0.73 & 0.74 & 0.76 & 0.77 & 0.80 & 0.80 & 0.80 & 0.80 & 0.78 & 0.76 \\
\hline & 75 & 0.66 & 0.70 & 0.70 & 0.72 & 0.73 & 0.74 & 0.77 & 0.77 & 0.77 & 0.77 & 0.76 & 0.73 \\
\hline & 70 & 0.64 & 0.67 & 0.67 & 0.69 & 0.71 & 0.72 & 0.75 & 0.74 & 0.74 & 0.74 & 0.73 & 0.71 \\
\hline & 65 & 0.62 & 0.65 & 0.65 & 0.67 & 0.68 & 0.70 & 0.72 & 0.72 & 0.71 & 0.71 & 0.70 & 0.68 \\
\hline & 60 & 0.60 & 0.63 & 0.63 & 0.65 & 0.66 & 0.67 & 0.70 & 0.69 & 0.69 & 0.69 & 0.68 & 0.66 \\
\hline & 55 & 0.58 & 0.61 & 0.61 & 0.63 & 0.64 & 0.65 & 0.68 & 0.67 & 0.67 & 0.67 & 0.66 & 0.64 \\
\hline & 50 & 0.57 & 0.60 & 0.60 & 0.61 & 0.62 & 0.64 & 0.66 & 0.65 & 0.65 & 0.65 & 0.64 & 0.62 \\
\hline & 45 & 0.55 & 0.58 & 0.58 & 0.60 & 0.61 & 0.62 & 0.64 & 0.63 & 0.63 & 0.63 & 0.62 & 0.60 \\
\hline & 40 & 0.54 & 0.56 & 0.56 & 0.58 & 0.59 & 0.60 & 0.62 & 0.61 & 0.61 & 0.61 & 0.60 & 0.58 \\
\hline & 35 & 0.52 & 0.54 & 0.54 & 0.56 & 0.57 & 0.58 & 0.60 & 0.59 & 0.59 & 0.59 & 0.59 & 0.57 \\
\hline & 30 & 0.51 & 0.53 & 0.53 & 0.54 & 0.55 & 0.56 & 0.58 & 0.57 & 0.57 & 0.57 & 0.57 & 0.55 \\
\hline & 25 & 0.49 & 0.51 & 0.51 & 0.53 & 0.53 & 0.54 & 0.56 & 0.55 & 0.55 & 0.56 & 0.55 & 0.53 \\
\hline & 20 & 0.47 & 0.49 & 0.49 & 0.50 & 0.51 & 0.52 & 0.54 & 0.53 & 0.53 & 0.53 & 0.52 & 0.51 \\
\hline & 15 & 0.45 & 0.46 & 0.47 & 0.48 & 0.49 & 0.49 & 0.51 & 0.50 & 0.50 & 0.51 & 0.50 & 0.48 \\
\hline & 10 & 0.43 & 0.44 & 0.44 & 0.45 & 0.46 & 0.46 & 0.48 & 0.47 & 0.48 & 0.48 & 0.47 & 0.45 \\
\hline & 5 & 0.39 & 0.40 & 0.40 & 0.41 & 0.42 & 0.43 & 0.44 & 0.43 & 0.44 & 0.44 & 0.43 & 0.42 \\
\hline & 1 & 0.33 & 0.34 & 0.34 & 0.35 & 0.35 & 0.36 & 0.37 & 0.37 & 0.36 & 0.38 & 0.37 & 0.35 \\
\hline
\end{tabular}

* population with the same age structure as the French women 1999 census population aged 20-74.

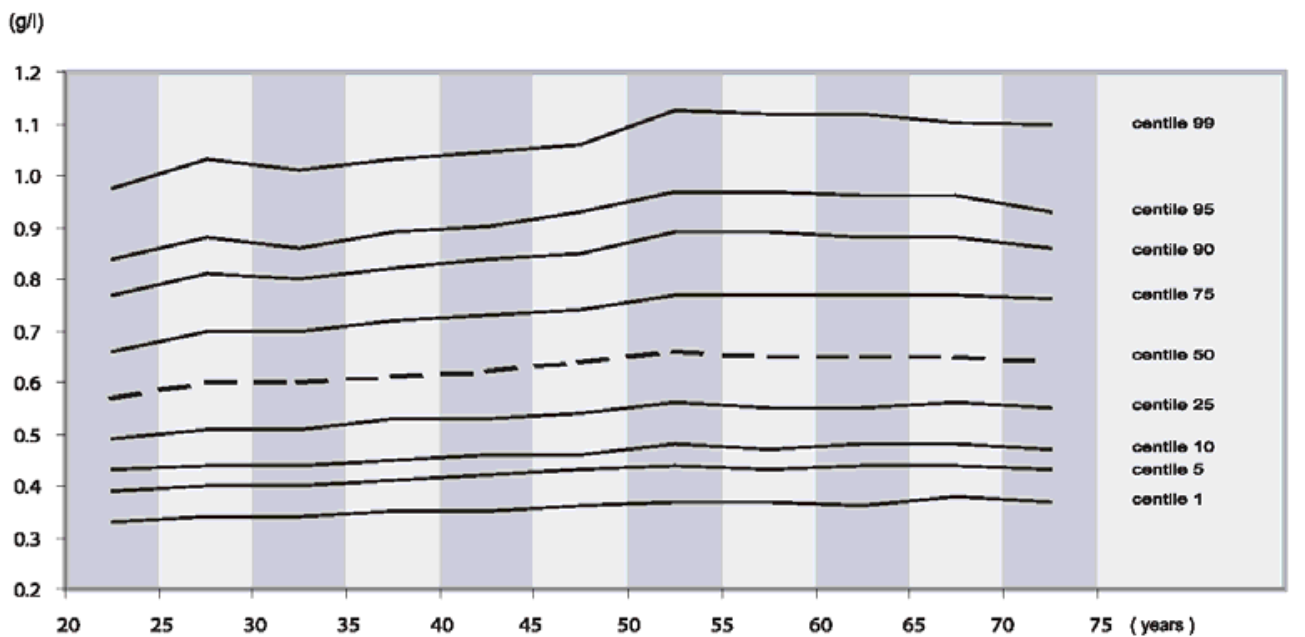


Systolic blood pressure ( $\mathrm{mmHg}$ ) : centiles by age class on 65,372 men from preventive health centers (IRSA, France)

\begin{tabular}{|c|c|c|c|c|c|c|c|c|c|c|c|c|c|}
\hline \multicolumn{14}{|c|}{ Age (years) } \\
\hline & & $20-24$ & $25-29$ & $30-34$ & $35-39$ & $40-44$ & $45-49$ & $50-54$ & $55-59$ & $60-64$ & $65-69$ & $70-74$ & 20-74 * \\
\hline \multirow{2}{*}{\multicolumn{2}{|c|}{ mean }} & 3,436 & 4,812 & 7,068 & 8,850 & 8,885 & 9,077 & 9,038 & 6,474 & 3,649 & 2,684 & 1,399 & 19,126 \\
\hline & & 126.9 & 127.9 & 128.5 & 129.3 & 131.0 & 133.7 & 136.6 & 139.8 & 142.5 & 145.7 & 147.9 & 134.0 \\
\hline \multicolumn{2}{|c|}{ standard deviation } & 10.5 & 10.9 & 11.2 & 11.7 & 12.8 & 14.2 & 15.1 & 16.4 & 16.9 & 17.9 & 17.7 & 15.3 \\
\hline \multirow{21}{*}{ centiles } & 99 & 155 & 159 & 160 & 162 & 170 & 180 & 182 & 188 & 194 & 199 & 196 & 183 \\
\hline & 95 & 140 & 145 & 146 & 150 & 153 & 160 & 164 & 170 & 175 & 180 & 181 & 160 \\
\hline & 90 & 140 & 140 & 140 & 140 & 145 & 150 & 155 & 160 & 163 & 170 & 170 & 152 \\
\hline & 85 & 139 & 140 & 140 & 140 & 140 & 146 & 150 & 155 & 159 & 161 & 165 & 148 \\
\hline & 80 & 135 & 136 & 139 & 140 & 140 & 143 & 147 & 150 & 154 & 160 & 160 & 144 \\
\hline & 75 & 134 & 135 & 135 & 137 & 140 & 140 & 145 & 150 & 150 & 155 & 159 & 140 \\
\hline & 70 & 131 & 133 & 134 & 135 & 137 & 140 & 140 & 145 & 150 & 150 & 155 & 140 \\
\hline & 65 & 130 & 130 & 131 & 133 & 135 & 139 & 140 & 144 & 146 & 150 & 151 & 139 \\
\hline & 60 & 130 & 130 & 130 & 130 & 133 & 136 & 140 & 140 & 145 & 149 & 150 & 135 \\
\hline & 55 & 130 & 130 & 130 & 130 & 130 & 135 & 138 & 140 & 141 & 145 & 149 & 134 \\
\hline & 50 & 128 & 130 & 130 & 130 & 130 & 132 & 135 & 140 & 140 & 144 & 145 & 131 \\
\hline & 45 & 125 & 127 & 128 & 130 & 130 & 130 & 134 & 138 & 140 & 140 & 144 & 130 \\
\hline & 40 & 124 & 125 & 125 & 126 & 129 & 130 & 130 & 135 & 139 & 140 & 140 & 130 \\
\hline & 35 & 121 & 123 & 124 & 125 & 125 & 130 & 130 & 132 & 135 & 140 & 140 & 129 \\
\hline & 30 & 120 & 120 & 120 & 122 & 125 & 126 & 130 & 130 & 134 & 137 & 140 & 125 \\
\hline & 25 & 120 & 120 & 120 & 120 & 121 & 125 & 126 & 130 & 130 & 135 & 137 & 123 \\
\hline & 20 & 120 & 120 & 120 & 120 & 120 & 120 & 125 & 128 & 130 & 130 & 135 & 120 \\
\hline & 15 & 117 & 118 & 119 & 120 & 120 & 120 & 120 & 124 & 127 & 130 & 130 & 120 \\
\hline & 10 & 114 & 115 & 115 & 115 & 116 & 119 & 120 & 120 & 123 & 125 & 129 & 118 \\
\hline & 5 & 110 & 110 & 110 & 110 & 110 & 113 & 115 & 115 & 120 & 120 & 120 & 112 \\
\hline & 1 & 105 & 104 & 105 & 105 & 105 & 105 & 108 & 108 & 110 & 110 & 111 & 105 \\
\hline
\end{tabular}

" population with the same age structure as the French men 1999 census population aged 20-74.

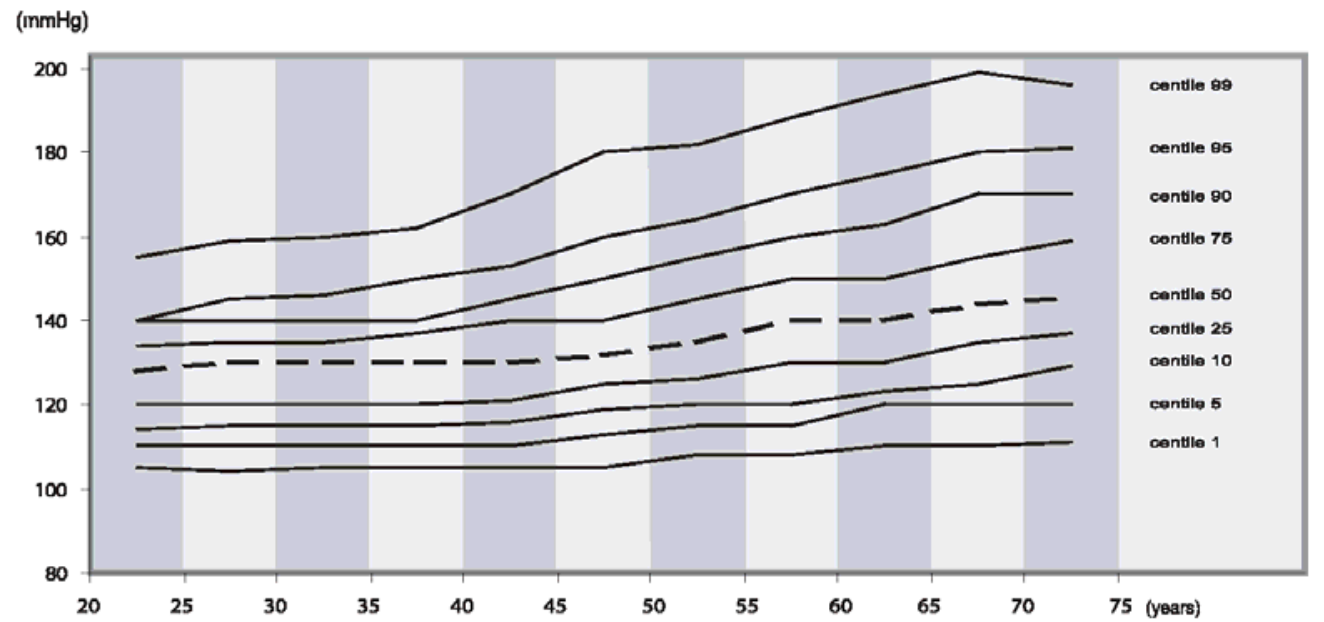


Systolic blood pressure $(\mathrm{mmHg})$ : centiles by age class on 65,510 women from preventive health centers (IRSA, France)

\begin{tabular}{|c|c|c|c|c|c|c|c|c|c|c|c|c|c|}
\hline & & \multicolumn{10}{|c|}{ Age (years) } & \multirow[b]{2}{*}{$70-74$} & \multirow[b]{2}{*}{$20-74$} \\
\hline & & 20-24 & $25-29$ & $30-34$ & $35-39$ & $40-44$ & $45-49$ & $50-54$ & $55-59$ & $60-64$ & $65-69$ & & \\
\hline \multicolumn{2}{|l|}{$\mathrm{n}$} & 5,261 & 5,398 & 7,264 & 7,368 & 8,558 & 8,879 & 8,619 & 6,655 & 3,509 & 2,580 & 1,419 & 19,874 \\
\hline \multicolumn{2}{|l|}{ mean } & 117.8 & 116.9 & 117.2 & 118.5 & 121.4 & 125.0 & 128.5 & 132.4 & 135.8 & 139.2 & 143.2 & 125.5 \\
\hline \multicolumn{2}{|c|}{ standard devlation } & 10.5 & 10.9 & 11.8 & 12.4 & 13.7 & 14.7 & 15.3 & 16.0 & 16.2 & 16.7 & 17.6 & 16.4 \\
\hline \multirow{21}{*}{ centiles } & 99 & 140 & 140 & 149 & 153 & 160 & 170 & 173 & 180 & 180 & 186 & 195 & 175 \\
\hline & 95 & 135 & 135 & 137 & 140 & 142 & 150 & 154 & 160 & 163 & 170 & 176 & 155 \\
\hline & 90 & 130 & 130 & 131 & 135 & 140 & 141 & 147 & 150 & 155 & 160 & 165 & 146 \\
\hline & 85 & 130 & 130 & 130 & 130 & 135 & 140 & 142 & 148 & 150 & 155 & 160 & 140 \\
\hline & 80 & 127 & 125 & 127 & 130 & 131 & 136 & 140 & 144 & 148 & 150 & 155 & 140 \\
\hline & 75 & 125 & 124 & 125 & 126 & 130 & 134 & 140 & 140 & 145 & 150 & 151 & 135 \\
\hline & 70 & 122 & 121 & 121 & 125 & 130 & 130 & 135 & 140 & 142 & 146 & 150 & 131 \\
\hline & 65 & 120 & 120 & 120 & 121 & 125 & 130 & 133 & 139 & 140 & 144 & 149 & 130 \\
\hline & 60 & 120 & 120 & 120 & 120 & 124 & 130 & 130 & 135 & 140 & 140 & 145 & 130 \\
\hline & 55 & 120 & 120 & 120 & 120 & 120 & 125 & 130 & 134 & 139 & 140 & 144 & 125 \\
\hline & 50 & 120 & 117 & 117 & 120 & 120 & 124 & 130 & 130 & 135 & 140 & 141 & 123 \\
\hline & 45 & 117 & 115 & 115 & 116 & 120 & 120 & 126 & 130 & 133 & 138 & 140 & 120 \\
\hline & 40 & 115 & 114 & 114 & 115 & 119 & 120 & 124 & 130 & 130 & 135 & 140 & 120 \\
\hline & 35 & 114 & 111 & 111 & 113 & 115 & 120 & 120 & 126 & 130 & 132 & 136 & 120 \\
\hline & 30 & 110 & 110 & 110 & 110 & 114 & 117 & 120 & 124 & 129 & 130 & 134 & 116 \\
\hline & 25 & 110 & 110 & 110 & 110 & 110 & 115 & 120 & 120 & 125 & 130 & 130 & 114 \\
\hline & 20 & 110 & 108 & 108 & 110 & 110 & 112 & 115 & 120 & 120 & 125 & 130 & 110 \\
\hline & 15 & 107 & 105 & 105 & 105 & 108 & 110 & 112 & 116 & 120 & 120 & 128 & 110 \\
\hline & 10 & 105 & 104 & 102 & 103 & 105 & 108 & 110 & 112 & 116 & 120 & 120 & 106 \\
\hline & 5 & 100 & 100 & 100 & 100 & 100 & 103 & 105 & 108 & 110 & 112 & 117 & 102 \\
\hline & 1 & 95 & 94 & 91 & 94 & 95 & 95 & 98 & 100 & 100 & 105 & 105 & 95 \\
\hline
\end{tabular}

* population with the same age structure as the French women 1999 census population aged 20-74.

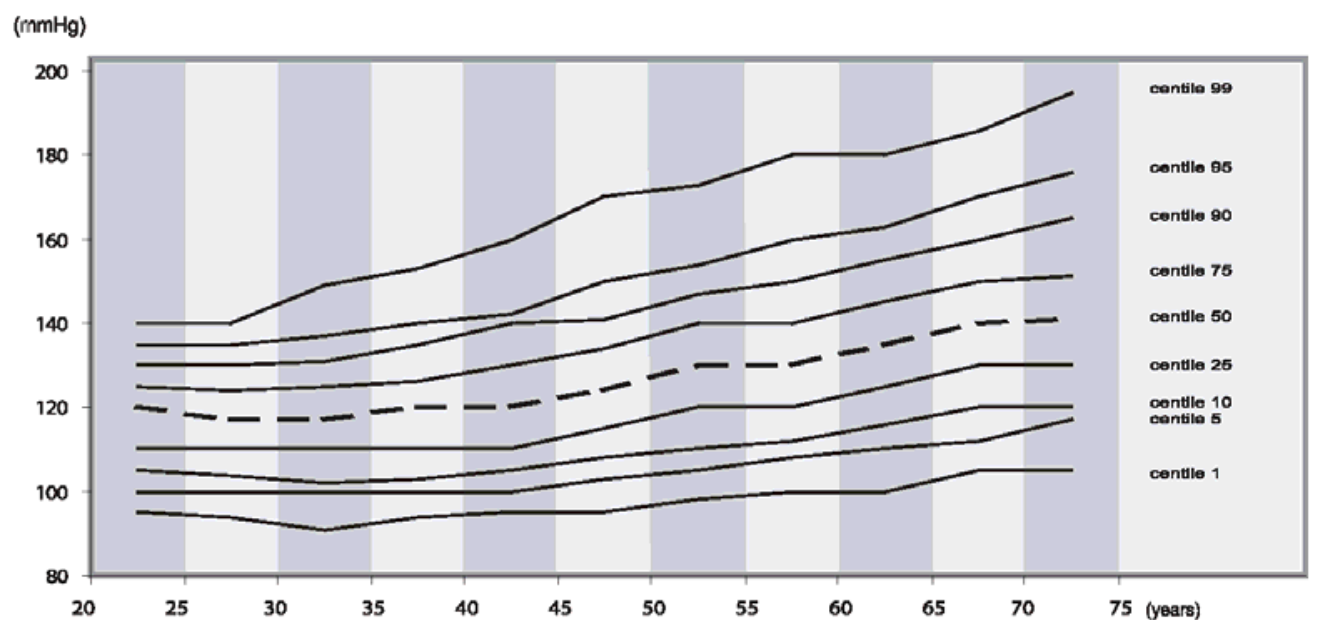


Diastolic blood pressure ( $\mathrm{mmHg}$ ) : centiles by age class on 65,372 men from preventive health centers (IRSA, France)

\begin{tabular}{|c|c|c|c|c|c|c|c|c|c|c|c|c|c|}
\hline \multicolumn{14}{|c|}{ Age (years) } \\
\hline & & $20-24$ & $25-29$ & $30-34$ & $35-39$ & $40-44$ & $45-49$ & 50-54 & $55-59$ & $60-64$ & $65-69$ & $70-74$ & $20-74 *$ \\
\hline \multicolumn{2}{|l|}{$n$} & 3,436 & 4,812 & 7,068 & 8,850 & 8,885 & 9,077 & 9,038 & 6,474 & 3,649 & 2,684 & 1,399 & 19,126 \\
\hline \multicolumn{2}{|l|}{ mean } & 73.0 & 75.4 & 76.5 & 78.1 & 80.0 & 81.6 & 83.0 & 83.9 & 83.8 & 83.7 & 83.1 & 79.7 \\
\hline \multicolumn{2}{|c|}{ standard deviation } & 8.0 & 8.1 & 8.3 & 8.7 & 9.4 & 9.8 & 9.8 & 9.9 & 9.7 & 9.5 & 9.5 & 9.8 \\
\hline \multirow{21}{*}{ centiles } & 99 & 91 & 95 & 100 & 101 & 107 & 110 & 110 & 110 & 110 & 110 & 110 & 107 \\
\hline & 95 & 85 & 90 & 90 & 91 & 97 & 100 & 100 & 100 & 100 & 100 & 100 & 97 \\
\hline & 90 & 81 & 85 & 86 & 90 & 90 & 94 & 95 & 96 & 95 & 95 & 95 & 90 \\
\hline & 85 & 80 & 82 & 85 & 86 & 90 & 90 & 91 & 93 & 92 & 92 & 91 & 90 \\
\hline & 80 & 80 & 80 & 82 & 85 & 87 & 90 & 90 & 90 & 90 & 90 & 90 & 88 \\
\hline & 75 & 80 & 80 & 80 & 83 & 85 & 88 & 90 & 90 & 90 & 90 & 90 & 85 \\
\hline & 70 & 80 & 80 & 80 & 81 & 84 & 85 & 88 & 90 & 89 & 89 & 88 & 84 \\
\hline & 65 & 77 & 80 & 80 & 80 & 82 & 85 & 85 & 87 & 87 & 87 & 86 & 81 \\
\hline & 60 & 75 & 79 & 80 & 80 & 80 & 82 & 85 & 85 & 85 & 85 & 85 & 80 \\
\hline & 55 & 74 & 77 & 80 & 80 & 80 & 80 & 83 & 85 & 85 & 84 & 84 & 80 \\
\hline & 50 & 72 & 75 & 77 & 80 & 80 & 80 & 81 & 83 & 82 & 82 & 81 & 80 \\
\hline & 45 & 70 & 75 & 75 & 79 & 80 & 80 & 80 & 80 & 80 & 80 & 80 & 80 \\
\hline & 40 & 70 & 72 & 75 & 77 & 80 & 80 & 80 & 80 & 80 & 80 & 80 & 79 \\
\hline & 35 & 70 & 70 & 72 & 75 & 77 & 80 & 80 & 80 & 80 & 80 & 80 & 76 \\
\hline & 30 & 70 & 70 & 70 & 73 & 75 & 78 & 80 & 80 & 80 & 80 & 80 & 75 \\
\hline & 25 & 70 & 70 & 70 & 70 & 73 & 75 & 78 & 80 & 80 & 80 & 78 & 72 \\
\hline & 20 & 67 & 70 & 70 & 70 & 70 & 73 & 75 & 77 & 77 & 77 & 75 & 70 \\
\hline & 15 & 65 & 69 & 70 & 70 & 70 & 70 & 72 & 74 & 75 & 75 & 73 & 70 \\
\hline & 10 & 61 & 65 & 67 & 69 & 70 & 70 & 70 & 70 & 70 & 70 & 70 & 70 \\
\hline & 5 & 60 & 60 & 61 & 65 & 65 & 69 & 70 & 70 & 70 & 70 & 70 & 65 \\
\hline & 1 & 57 & 60 & 60 & 60 & 60 & 60 & 60 & 60 & 60 & 60 & 61 & 60 \\
\hline
\end{tabular}

" population with the same age structure as the French men 1999 census population aged 20-74.

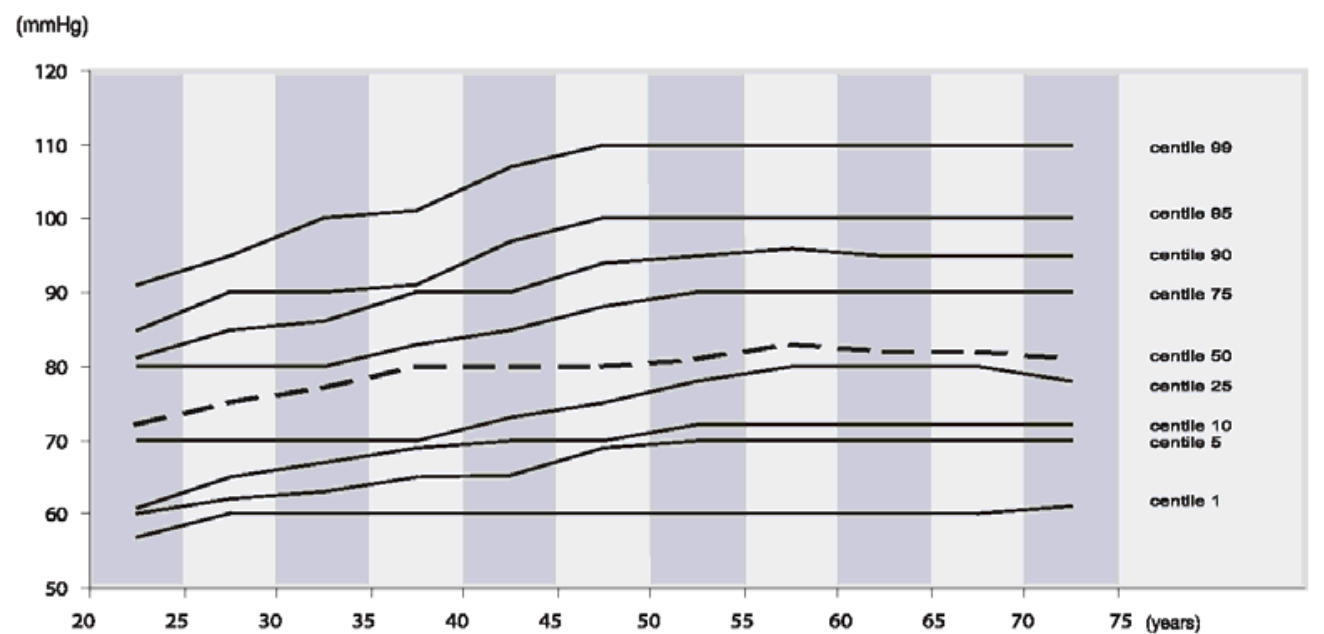


Diastolic blood pressure $(\mathrm{mmHg})$ : centiles by age class on 65,510 women from preventive health centers (IRSA, France)

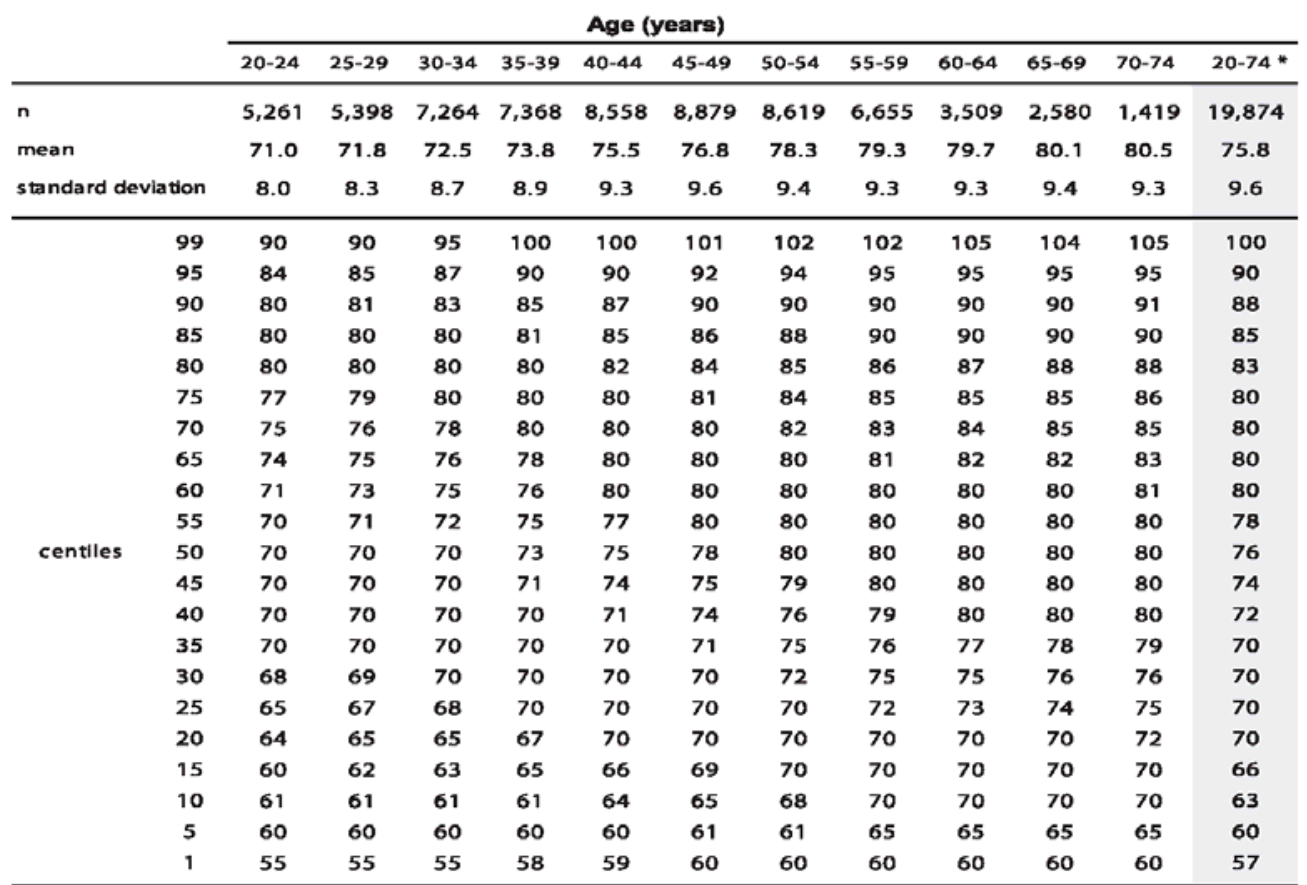

* population with the same age structure as the French women 1999 census population aged 20-74.

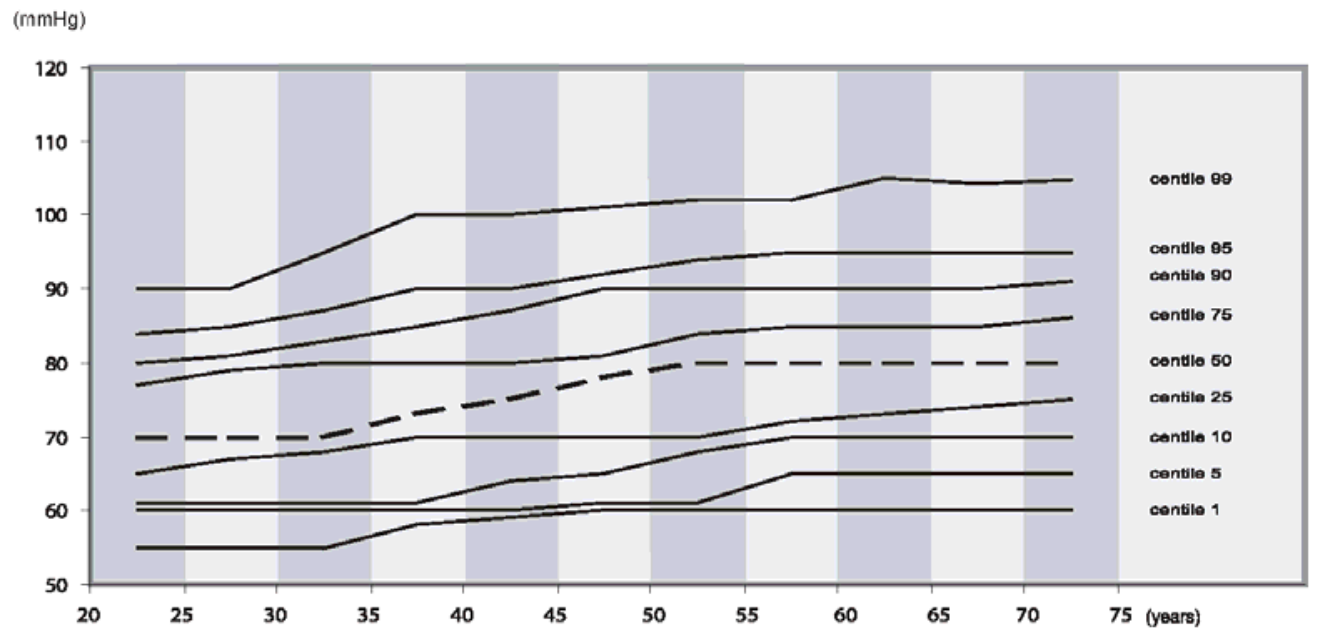

